\title{
Technology Implementation Plan
}

Fully Ceramic Microencapsulated Fuel for Commercial Light Water Reactor Application

Approved for public release; distribution is unlimited
L. L. Snead

K. A. Terrani

J. J. Powers

A. Worrall

K. R. Robb

M. A. Snead

April, 2015 


\section{DOCUMENT AVAILABILITY}

Reports produced after January 1, 1996, are generally available free via US Department of Energy (DOE) SciTech Connect.

Website http://www.osti.gov/scitech/

Reports produced before January 1, 1996, may be purchased by members of the public from the following source:

National Technical Information Service

5285 Port Royal Road

Springfield, VA 22161

Telephone 703-605-6000 (1-800-553-6847)

TDD 703-487-4639

Fax 703-605-6900

E-mail info@ntis.gov

Website http://www.ntis.gov/help/ordermethods.aspx

Reports are available to DOE employees, DOE contractors, Energy Technology Data Exchange representatives, and International Nuclear Information System representatives from the following source:

Office of Scientific and Technical Information

PO Box 62

Oak Ridge, TN 37831

Telephone 865-576-8401

Fax 865-576-5728

E-mail reports@osti.gov

Website http://www.osti.gov/contact.html

This report was prepared as an account of work sponsored by an
agency of the United States Government. Neither the United States
Government nor any agency thereof, nor any of their employees,
makes any warranty, express or implied, or assumes any legal liability
or responsibility for the accuracy, completeness, or usefulness of any
information, apparatus, product, or process disclosed, or represents
that its use would not infringe privately owned rights. Reference herein
to any specific commercial product, process, or service by trade name,
trademark, manufacturer, or otherwise, does not necessarily constitute
or imply its endorsement, recommendation, or favoring by the United
States Government or any agency thereof. The views and opinions of
authors expressed herein do not necessarily state or reflect those of
the United States Government or any agency thereof.




\title{
TECHNOLOGY IMPLEMENTATION PLAN
}

\section{FULLY CERAMIC MICROENCAPSULATED FUEL FOR COMMERCIAL LIGHT WATER REACTOR APPLICATION}

\author{
L. L. Snead \\ K. A. Terrani \\ J. J. Powers \\ A. Worrall \\ K. R. Robb \\ M. A. Snead
}

April, 2015

Prepared by

OAK RIDGE NATIONAL LABORATORY

Oak Ridge, TN 37831-6283

managed by

UT-BATTELLE, LLC

for the

US DEPARTMENT OF ENERGY

under contract DE-AC05-00OR22725 



\section{CONTENTS}

$\begin{array}{rlll}\text { Page } & \end{array}$

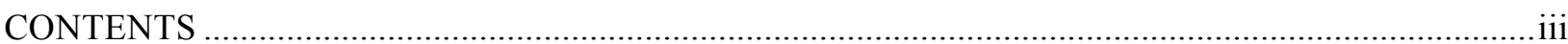



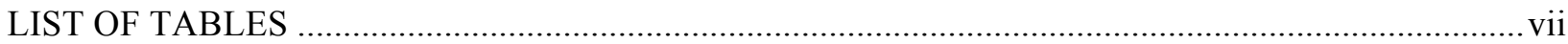



1.1 FULLY CERAMIC MICROENCAPSULATED FUEL …............................................. 1

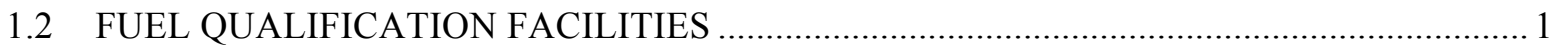

1.2.1 Advanced Text Reactor (ATR): Idaho Falls, Idaho-USA ........................................... 1

1.2.2 Halden Boiling Water Reactor (HBWR) Facility: Halden-Norway …........................... 4

1.2.3 High Flux Isotope Reactor (HFIR): Oak Ridge, Tennessee-USA …….......................... 5

1.2.4 Transient Reactor Test Facility (TREAT) Facility: Idaho Falls, Idaho-USA ................ 6

2. DESIGN AND UTILIZATION OF FCM IN NORMAL COMMERCIAL APPLICATION...............8

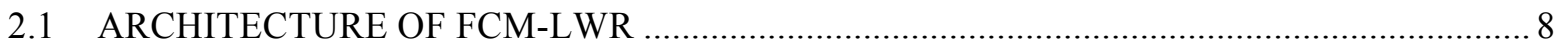

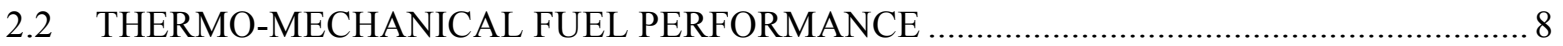

2.3 WHOLE CORE THERMO-MECHANICAL FUEL PERFORMANCE ............................... 9



3.1 ATF ANALYSIS DURING THE MATERIAL DEVELOPMENT PHASE .......................... 13



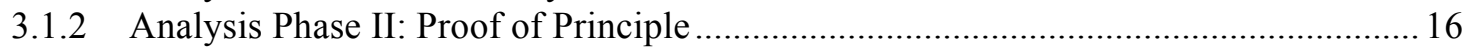

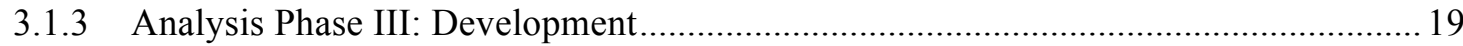

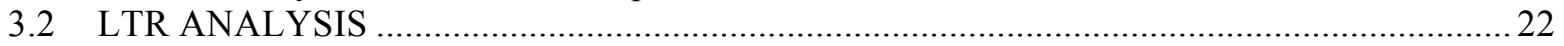



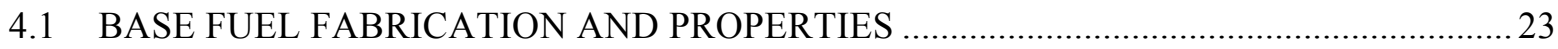

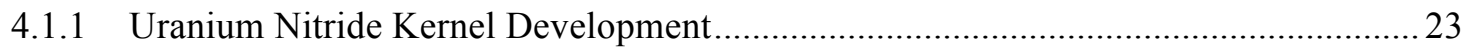

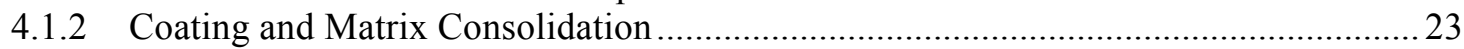

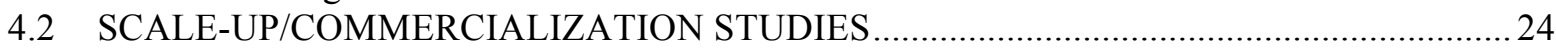

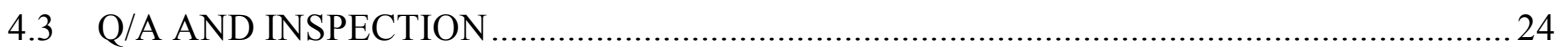

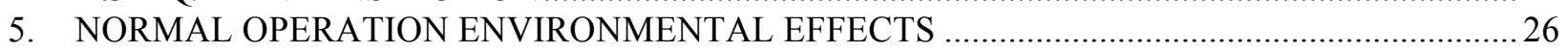



5.1.1 Surface Heat Flux Limits of FCM-LWR Fuel (FCM-SH Series) .................................2 27

5.2 FUEL QUALIFICATION FOR NORMAL OPERATING CONDITIONS ..............................29

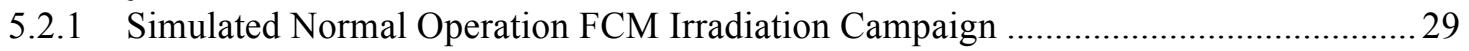

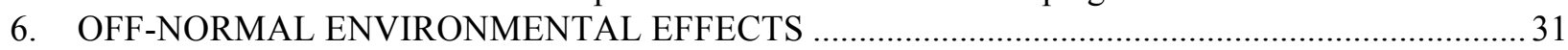

6.1 CLADDING FAILURE DURING NORMAL OPERATION ............................................ 31



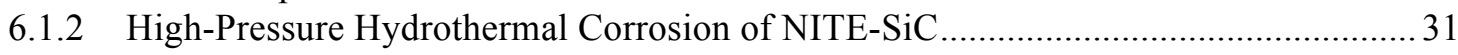

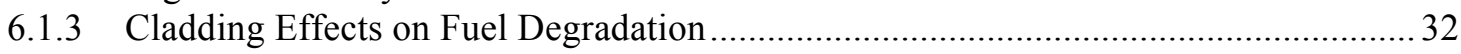

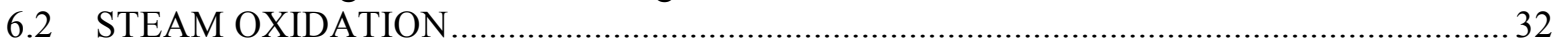

6.2.1 Task I: High-Temperature Separate Effects Steam Oxidation of FCM Fuel

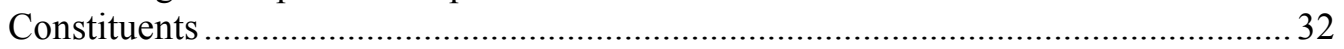

6.2.2 Task II: Integral FCM Fuel Rodlet Testing in High-Temperature Steam..................... 33

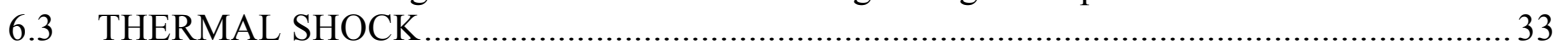

6.3.1 Task I: High-Temperature Separate Effects Steam Oxidation of FCM Fuel

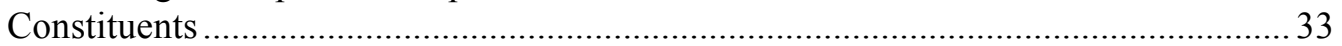

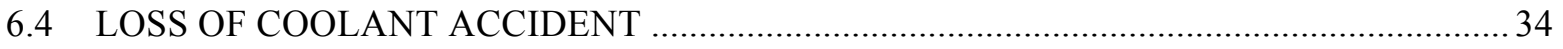

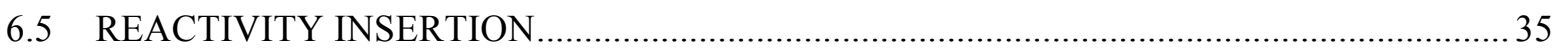

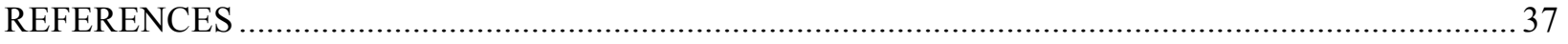





\section{LIST OF FIGURES}

Figure

Page

Figure 1.2.1.1: Cross section of the ATR core including the range of neutron-irradiation experimental sites. 2

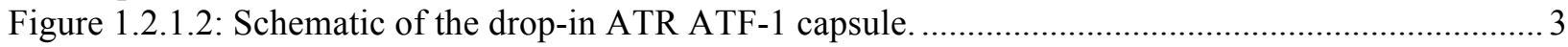

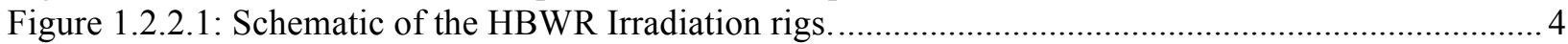

Figure 1.2.3.1: Cross section of the HFIR core including the range of neutron-irradiation

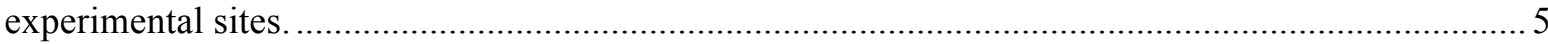

Figure 1.2.3.2: Schematic of the Thermosyphon Irradiation Facility at HFIR (not to scale). ................... 6

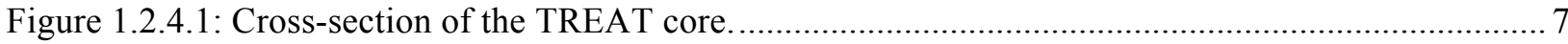





\section{LIST OF TABLES}

Table

Page

Table 5.1.1.1: HFIR FCM Property Investigation Matrix .................................................................2 27

Table 5.1.1.2: FCM SH Series Property Irradiation Matrix. Linear heat rate assumes a nominal



Table 5.2.1.1: Summary of the FCM NO Fuel Qualification irradiation series to be carried out in the HBWR 30

Table 6.4.1: Summary of the FCM NO Fuel Qualification irradiation series to be carried out in the HBWR and Severe Accident Test Facility. 35

Table 6.5.1: Summary of the FCM Reactivity Insertion (RI) experiment. 36 


\section{TECHNOLOGY OVERVIEW}

\subsection{FULLY CERAMIC MICROENCAPSULATED FUEL}

The fully ceramic microencapsulated (FCM) fuel [1-2] consists of tristructural isotropic (TRISO) particles embedded inside a fully dense $\mathrm{SiC}$ matrix and is intended for utilization in commercial light water reactor application. This fuel design differs widely from the previous dispersion type fuel approaches, since the damage due to $100 \mathrm{MeV}$ fission fragments and noble gas release is fully contained within the TRISO particle and the inert SiC matrix is solely exposed to neutron irradiation. In addition to offering exceptional stability under neutron irradiation conditions, the thermal conductivity of the SiC matrix, even in the irradiated condition, is at least two times higher than that of uranium dioxide. This implies that while operating at the same linear heat rating as a commercial $\mathrm{UO}_{2}$ fuel, the temperature gradient across the FCM fuel is significantly reduced. Even accounting for the temperature drop across the fuel cladding gap, fuel centerline temperatures on the order of a few hundred degrees above that of the coolant are expected. The fuel development and qualification process for FCM fuel has benefited from and will continue to benefit from decades of gas reactor TRISO fuel development and optimization activities, including the recent progress made as part of the DOE-NE Advanced Gas Reactor (AGR) experiments [3]. However, in contrast to the gas cooled reactor application, the significantly lower application temperature and replacement of graphite matrix by $\mathrm{SiC}$ for the Light Water Reactor (LWR) application raises a host of issues not previously addressed. Moreover, a range of practical issues involving fuel utilization, the performance of this new potential fuel under normal and off-normal operating conditions, and it's fabrication and development path into a viable commercial product require deliberate study.

\subsection{FUEL QUALIFICATION FACILITIES}

The qualification of the FCM fuel will require the use of a number of materials test reactors and radiological and hot cell facilities in the United States and abroad.

\subsubsection{Advanced Text Reactor (ATR): Idaho Falls, Idaho-USA}

The ATR is a light water moderated research reactor primarily designed and used to test materials to be used in larger-scale and prototype reactors. It can operate at a maximum power of $250 \mathrm{MW}$ and has a "Four Leaf Clover" design that allows for a variety of testing locations. The unique design allows for different flux in various locations and specialized systems also allow for certain experiments to be run at their own temperature and pressure. A cross section of the ATR core including the range of neutronirradiation experimental sites is provided in Figure 1.2.1.1. 


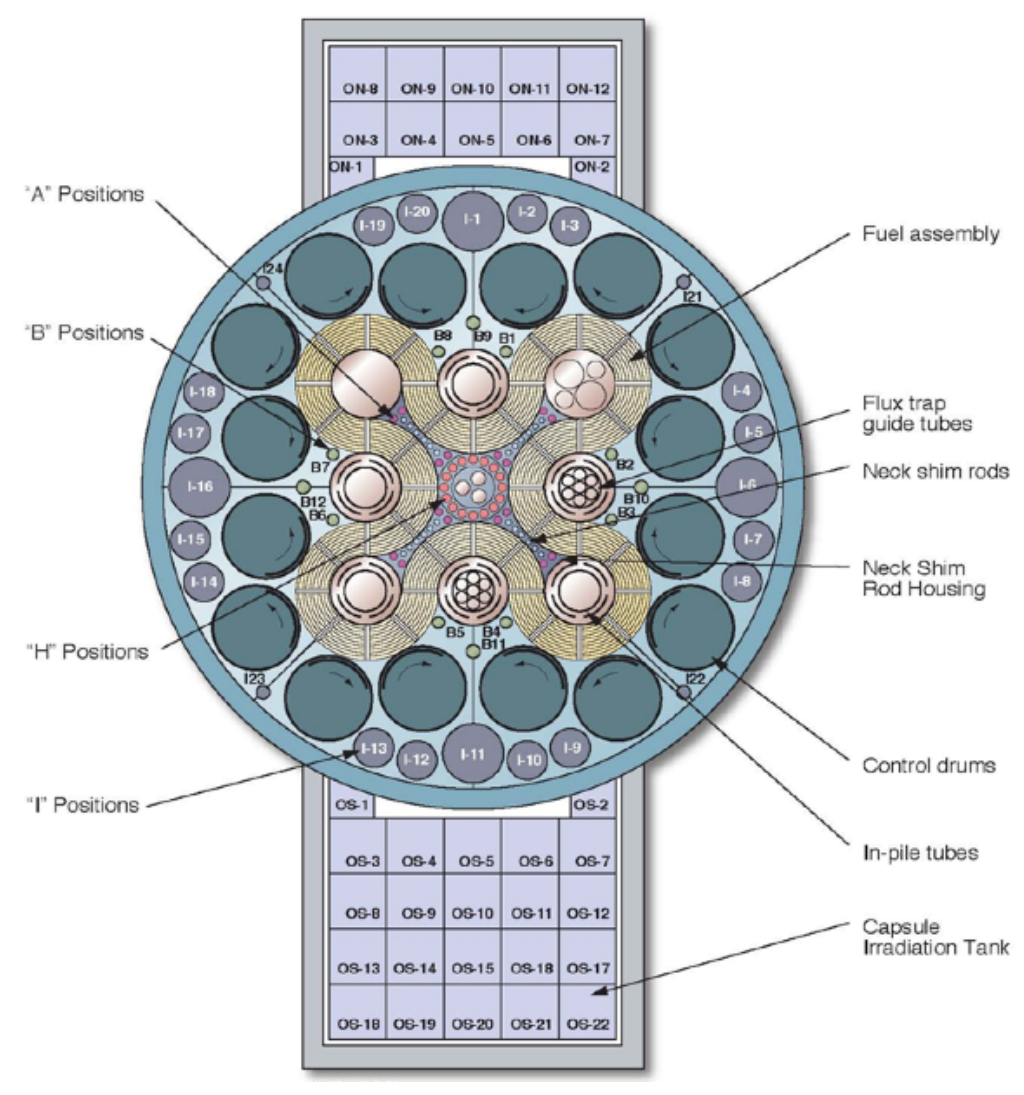

Figure 1.2.1.1: Cross section of the ATR core including the range of neutron-irradiation experimental sites.

The ATR core is designed to be as flexible as possible for research needs. It can be brought online and powered down safely as often as necessary to change experiments or perform maintenance. The reactor is also powered down automatically in the event of abnormal experimental conditions or power failure.

Components of the reactor core are replaced as necessary every 7-10 years to prevent fatigue due to exposure to radiation and to ensure experimenters always have a new reactor to work with. The neutron flux provided by the reactor can be either constant or variable, and each lobe of the four-leaf-clover design can be controlled independently to produce up to $10^{15}$ thermal neutron per second per square centimeter or $5 \cdot 10^{14}$ fast neutrons s $\mathrm{s}^{-1} \mathrm{~cm}^{-2}$. There are 77 different testing locations inside the reflector and another 34 low-intensity locations outside the core (see Figure 1.2.1.1), allowing many experiments to run simultaneously in different test environments. Test volumes up to 5.0 inches $(130 \mathrm{~mm})$ in diameter and 4 feet $(1.2 \mathrm{~m})$ long can be accommodated.

There are three types of generic experimental facilities that can be used for materials and fuels irradiation in the ATR: Static Capsule Experiments, In-Pile Loops, and Instrumented Capsules. For the current FCM qualification program is envisioned only to utilize the static capsules experiment capability of ATR, for which samples are contained in an inert environment within a stainless steel, zircaloy, aluminum capsule. For typical irradiations, if the tube is less than the full 48" reactor height, several capsules may be stacked. In some cases, it is desirable to test materials (such as fuel elements) in direct contact with the reactor coolant, in which case, the test capsule is not sealed.

The first FCM-specific irradiation is planned to be the DOE-sponsored accident tolerant fuel (ATF-1) capsule. The ATF-1 experiments will be a series of drop-in capsules tests based on an existing design 
used to test fueled rodlets in the ATR under conditions of temperature and power prototypic of LWRs. The basket containing three rods will be accommodated in either the small-I or large-B test positions in the ATR reflector (see Figure 1.2.1.1). Previous irradiation experiments performed using this design have all used the small-I positions, which were capable of achieving linear heat generation rates (LHGR) and cladding temperatures in the normal operating range for commercial pressurized water reactors (PWRs) $\left(160-230 \mathrm{~W} / \mathrm{cm}\right.$ and $350^{\circ} \mathrm{C}$, respectively). While the large-B positions offer a slightly higher flux level over the small-I positions, they can suffer from significant power swings (as much as 20\%) during a normal ATR cycle due to their proximity to ATR's Outer Shim Control Cylinders (OSCC), which rotate continuously throughout an ATR cycle, and which generally make these positions unattractive for fueled experiments. In contrast, the small-I positions are relatively insensitive to OSCC rotation $(<4 \%)$. For this reason, preliminary scoping analyses for the ATF-1 test series have focused on the small-I positions. Four (4) small-I positions exist in the ATR. These four small-I positions are designated as I-21 in the northeast (NE) corner, I-22 in the southeast (SE) corner, I-23 in the southwest (SW) corner, and I-24 in the northwest $(\mathrm{NW})$ corner of the ATR; these positions have nominal (unperturbed) flux levels of $8.4 \times 10^{13}$ $\mathrm{n} / \mathrm{cm}^{2}$-sec (thermal) and $3.2 \times 10^{12} \mathrm{n} / \mathrm{cm}^{2}$-sec (fast), although these vary depending on actual lobe operating powers during any particular cycle. At least 2 (and perhaps all 4) of these small-I or large-B positions are to be made available for use in the ATF-1 irradiation test series beginning in 2015.

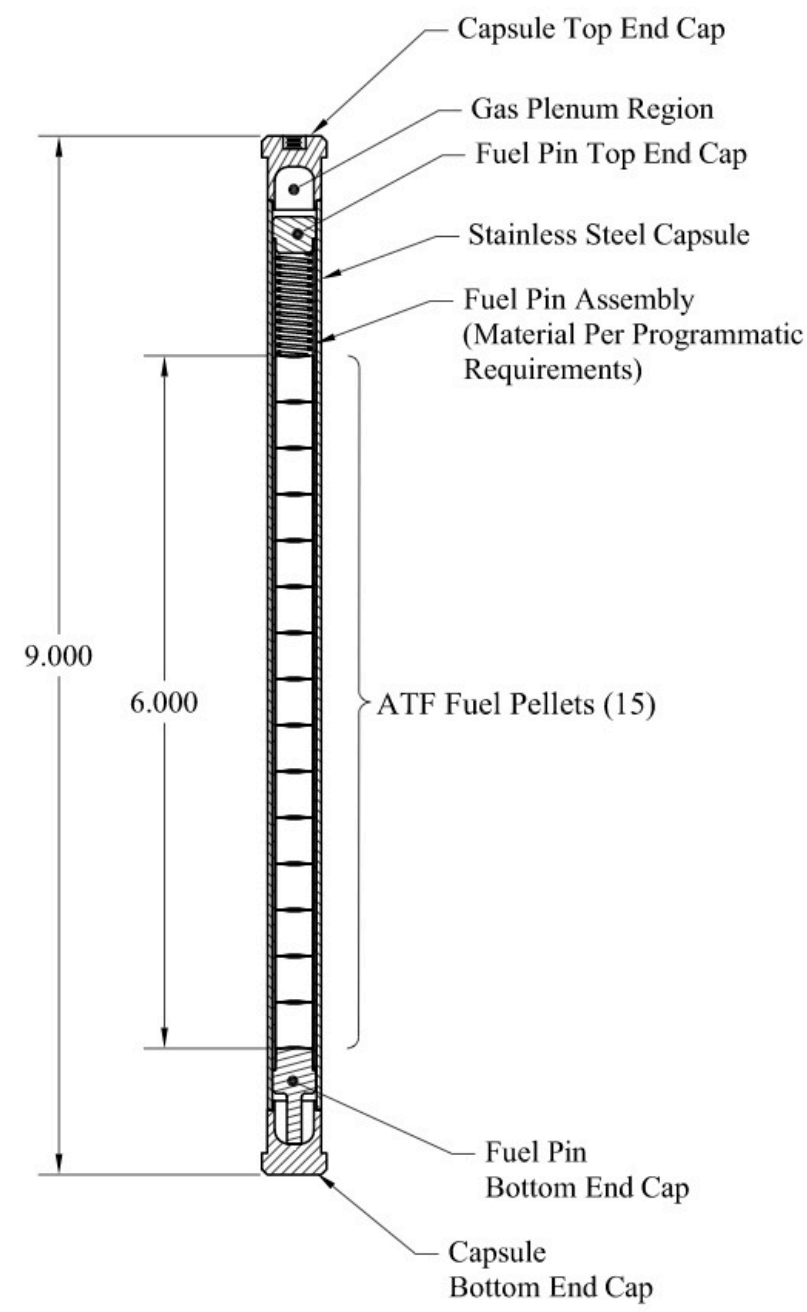

Figure 1.2.1.2: Schematic of the drop-in ATR ATF-1 capsule. 


\subsubsection{Halden Boiling Water Reactor (HBWR) Facility: Halden-Norway}

The HBWR is a natural circulation boiling heavy water reactor. The maximum power is $25 \mathrm{MW}$ (thermal), and the water temperature is $240^{\circ} \mathrm{C}$, corresponding to an operating pressure of $33.3 \mathrm{bar}$. The reactor pressure vessel is cylindrical with a rounded bottom (see Figure 1.2.2.1). It is made of carbon steel and the bottom and the cylindrical portion are clad with stainless steel. The flat reactor lid has individual penetrations for fuel assemblies, control stations and experimental equipment. The design working pressure of the HBWR pressure vessel is 40 bar with a saturation temperature of $250^{\circ} \mathrm{C}$. The hydraulic acceptance pressure test was carried out at 54 bar, $35 \%$ above the design pressure. The normal operating pressure is 33.6 bar, with corresponding saturation temperature of $240^{\circ} \mathrm{C}$. There are normally $2-3$ main shutdowns per year, dictated primarily by the experimental programs, and a few additional cooling downs for special tests. Current estimates indicate the reactor will be viable for operation until 2050.



Figure 1.2.2.1: Schematic of the HBWR Irradiation rigs.

The HBWR is a multi-purpose irradiation facility with supporting capabilities for post-irradiation examination. It will be used for both qualification of FCM under normal operating conditions and offnormal (accident) conditions. The primary capability within Halden that will be utilized are the instrumented fuel assemblies (IFA's). The IFA represents a test rig in which a set of fuel rods or material specimens can be irradiated. In most cases the test rigs are designed such that fuel rods and specimens can 
be exchanged, thus facilitating multipurpose use and economy. A number of heavily instrumented rigs to suit different test objectives have been developed and a handling compartment been installed for exchange of fuel rods and for interim inspection and measurements. Specific instrumentation will include fission-gas release and fuel swelling monitors. Within these experimental facilities fuel will be exposed to thermal neutron flux levels similar to that of commercial light-water reactors, in the range of $1-5 \times 10^{13}$ $\mathrm{n} / \mathrm{cm}^{2}$ with an associated fast neutron flux on the order of $0.5-3 \times 10^{13} \mathrm{n} / \mathrm{cm}^{2}$.

\subsubsection{High Flux Isotope Reactor (HFIR): Oak Ridge, Tennessee-USA}

HFIR is a beryllium-reflected, light-water-cooled and -moderated, flux-trap type reactor that uses highly enriched uranium-235 as the fuel. The preliminary conceptual design of the reactor was based on the "flux trap" principle, in which the reactor core consists of an annular region of fuel surrounding an unfueled moderating region or "island." Such a configuration permits fast neutrons leaking from the fuel to be moderated in the island and thus produces a region of very high thermal-neutron flux at the center of the island. Operating at $85 \mathrm{MW}$ the HFIR in essentially unparalleled in thermal and neutron flux with the flux trap. Moreover, variety of holes in the reflector provide sites in which to fuel and materials experiments can be carried out over a range of lower neutron fluxes. A cross section of the HFIR core including the range of neutron-irradiation experimental sites is provided in 1.2.3.1. The HFIR will be utilized primarily to provide property information regarding the performance of the FCM constituents under fast neutron irradiation in the Flux Trap region. This region provides a thermal and fast-neutron flux of 2.5 and $1 \times 10^{15}$ $\mathrm{n} / \mathrm{cm}^{2}$, respectively. Within the target region a number of irradiation vehicles can be considered ranging from fully instrumented capsules, full-length drop-in capsules similar to that depicted in the ATR schematic of Figure 1.2.1.2, or shorter non-instrumented static capsules often referred to as rabbit capsules. Such rabbit capsules have thus far been and will continue to be utilized for base property and TRISO behavior measurements.

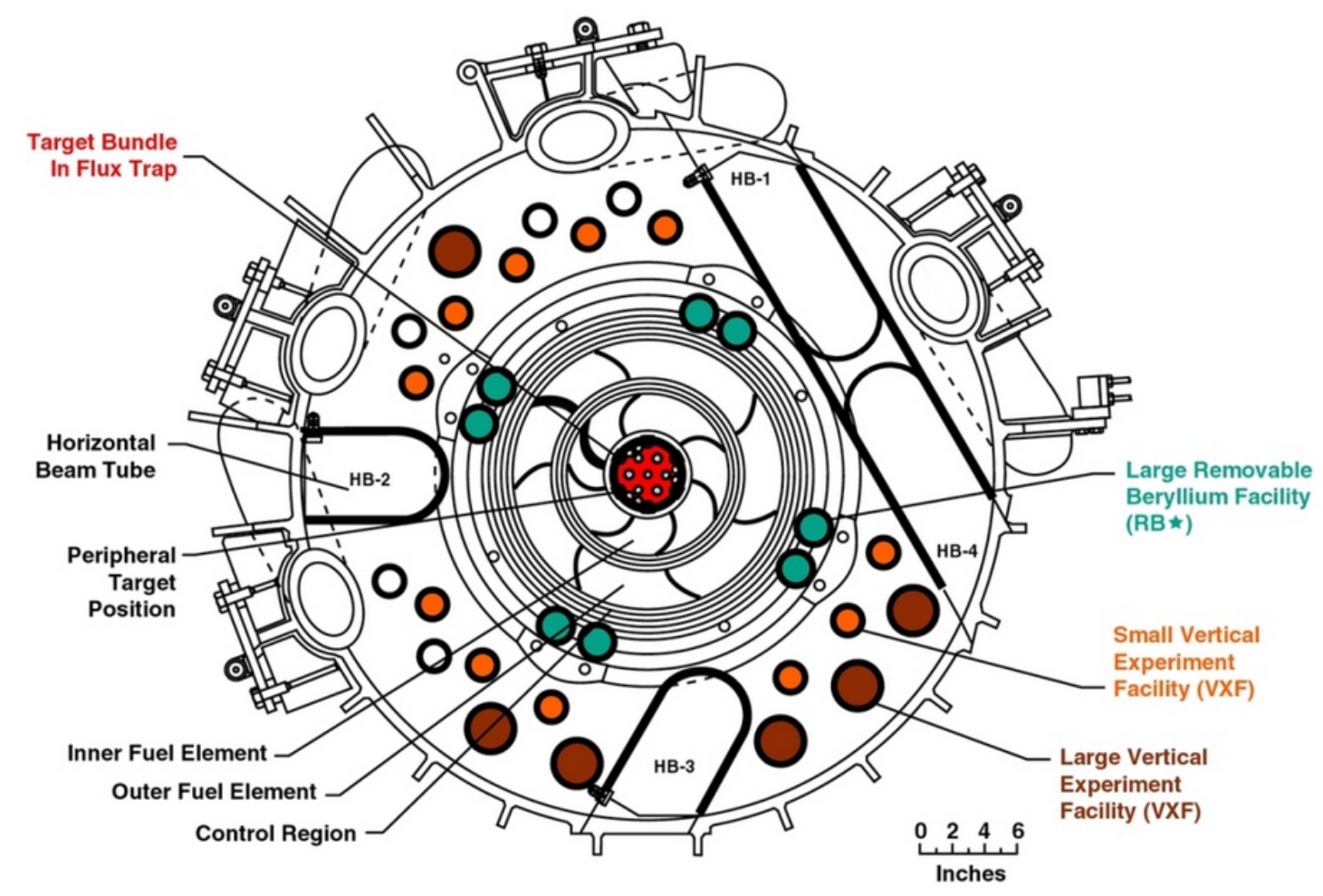

Figure 1.2.3.1: Cross section of the HFIR core including the range of neutron-irradiation experimental sites. 
In addition to the in-core (flux-trap) options, the HFIR offers irradiation of fissile-material-bearing fuel compacts such as the FCM in the newly developed thermosyphon [4]. This rig can accommodate 3 fuels rods and is placed in the Large VXF facility that is located away from the HFIR core inside the Be reflector. In this manner the thermal neutron flux is reduced to levels that are typical of LWR cores. The thermosyphon rig (Figure 1.2.3.2) takes advantage of natural circulation of the two-phase water coolant inside a closed flask to control the temperature and provide a flexible testing platform where a variety of lengths (up to $\sim 1 \mathrm{~m}$ ) and fuel rod diameters can be tested in contact with the coolant (Figure 1.2.3.2). The thermosyphon rig is capable of instrumentation such as thermocouples and rod internal pressure sensors.

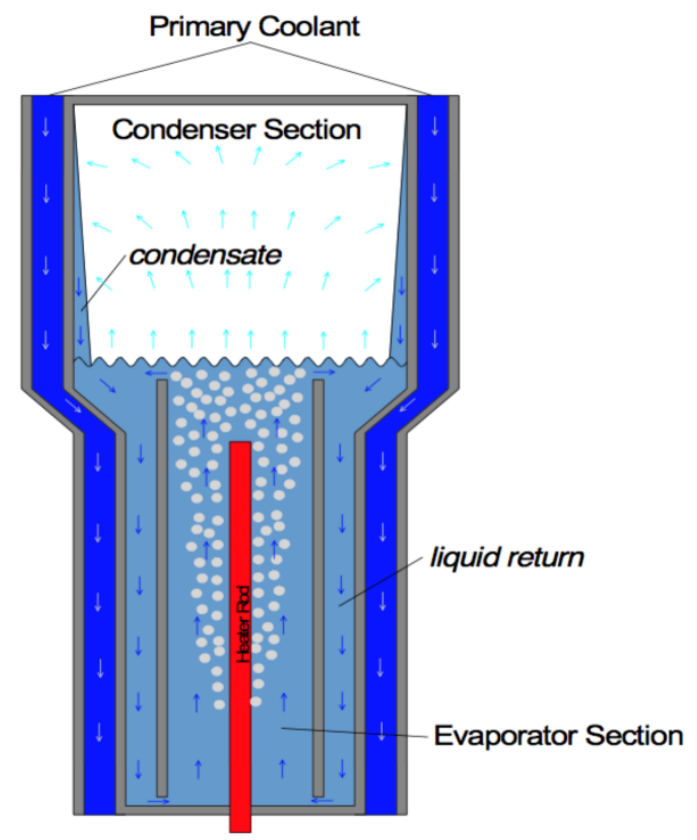

Figure 1.2.3.2: Schematic of the Thermosyphon Irradiation Facility at HFIR (not to scale).

With projected regular operations, the next major HFIR shutdown for a beryllium reflector replacement will not be necessary until approximately 2023. Beyond this the HFIR is currently authorized for operation through 2040.

\subsubsection{Transient Reactor Test Facility (TREAT) Facility: Idaho Falls, Idaho-USA}

The Transient Reactor Test Facility, commonly referred to as TREAT, is an air-cooled, thermal spectrum test facility designed to evaluate reactor fuels and structural materials. The architecture of the reactor allows for easy access to the core and visualization of the fuel article being tested. A cross section of the reactor core is provided in Figure 1.2.4.1.

TREAT was designed to:

- Induce intense fission heating in the nuclear fuel being tested.

- Test nuclear reactor fuels under severe reactor-accident conditions.

- Provide nondestructive test data through neutron radiography of fuel samples.

These capabilities are to be utilize for predicting safety margins for the FCM fuels and to use that data reactor design safety purposes. TREAT was historically used to study fuel meltdowns, metal-water reactions, interactions between overheated fuel and coolant, and the transient behavior of fuels for high- 
temperature systems. The open core design of TREAT also allows for the detailed monitoring of the experiments during the test. In its steady state of operation, TREAT can be used as a large neutron radiography facility that can non-destructively examine assemblies up to 15 feet long.

TREAT was specifically designed to test prototypic-sized reactor fuel pins and bundles under transient power conditions. During its 35 year operating history, it conducted thousands of transient experiments, going into cold standby in 1994. The Department of Energy is now moving to reinvigorate the TREAT capabilities and restart the reactor to support US and international nuclear energy programs. The assumed restart date is 2017 with initial experiments including fresh fuel to provide baseline fuel and TREAT facility performance information. Testing and qualification of advanced fuel is to start shortly after that time.

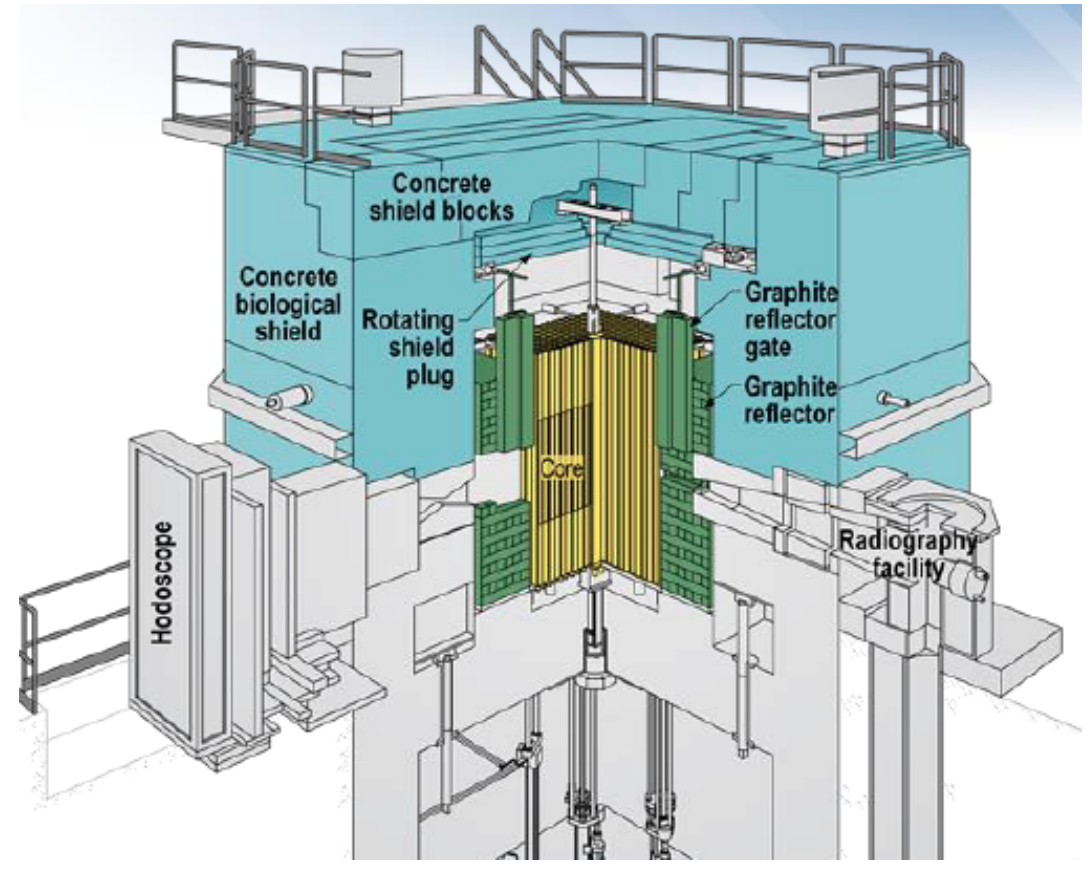

Figure 1.2.4.1: Cross-section of the TREAT core. 


\section{DESIGN AND UTILIZATION OF FCM IN NORMAL COMMERCIAL APPLICATION}

The FCM fuel specifically engineered for LWR application will be defined and proof-of-principle demonstration of modeling the thermo-mechanical fuel performance and behavior of an FCM fuel pin for normal operation (NO) conditions in existing LWRs using best estimate (BE) results obtained from the neutronics and thermal-hydraulics $(\mathrm{T} / \mathrm{H})$ areas (Tasks II-1 and II-2, Section 3). For FCM fuel, this thermo-mechanical fuel performance modeling and analysis will likely require 3 different levels of analysis: 1) single particle, as has been done in the past for TRISO fuel [5]; 2) single pellet, looking at the coupled behavior and performance of coated fuel particles in a SiC matrix; and 3) single rod, including a full pellet stack height into a cladding tube, as is more typically done for $\mathrm{UO}_{2}$ pellets in Zircaloy cladding for existing LWRs. Each of these modeling layers is semi-independent but also potentially coupled to the lower length scale model below it.

\subsection{ARCHITECTURE OF FCM-LWR}

Work Tasks and Output:

Utilizing materials property correlations and thermo-mechanical design analysis results (using the MOOSE-BISON platform) to define requirements for uranium nitride kernel, TRISO particle and compaction, and the matrix for FCM-LWR. Specific architecture, including layer thickness, quality assurance measures, and overall geometry will define the fuel attributed carried into fuel qualification irradiation.

Milestone 2.1.1: BISON modeling evaluation of TRISO-based FCM fuel performance and failure mechanisms in LWR environments.

Performance Period: January 2014 - September 2015

Milestone 2.1.2: Provide report with specific recommendation on fabrication and quality assurance parameters for the FCM-LWR fuel.

Performance Period: August 2015 - March 2016

\subsection{THERMO-MECHANICAL FUEL PERFORMANCE}

Material property correlations and engineering-scale models for thermo-mechanical fuel performance of FCM fuel particles, pellets, and pins in existing LWRs during NO conditions will be developed to support modeling and design activities. Specifically, qualitative and quantitative understanding of how the behavior predicted for FCM fuel differs from reference $\mathrm{UO}_{2}$ /Zircaloy fuel pins and assess whether these behavioral differences (e.g., gap closure rates and volumetric swelling as compared to axial growth under irradiation) are likely to have performance or operational impacts (e.g., changes to allowable power ramp rates for reactor startup or likely changes to fuel failure frequencies). Moreover, an understanding of how the FCM fuel behavior and performance in an LWR differs from behavior and performance in gas-cooled reactors, given the historical development of TRISO particles for gas-cooled reactors, will be addressed. Failure limits will be established based upon some combination of particle failure fraction limits and limiting failure modes for FCM fuel pellets and pins and then, using input conditions obtained from neutronics and T/H calculations in Analysis Phase II (Tasks II-1 and II-2, Section 3), perform failure analyses to assess whether FCM fuel design limits are likely to be exceeded in LWRs during steady-state NO conditions. Fuel design limits may vary based on assumptions made for the FCM pellets as well as which cladding material is used. If possible, estimate $\mathrm{BE}$ particle and pin failure probabilities and compare them to reference $\mathrm{UO}_{2} /$ Zircaloy fuel pins in those same conditions. 


\section{Output:}

This task should result in a conceptual understanding of behavior for FCM fuel particles, pellets, and pins as well as a preliminary assessment of whether FCM fuel design limits are likely to be exceeded during irradiation in LWRs during NO conditions.

Milestone 2.2.1: Summarize all findings into a written report and incorporate into later Analysis Phase II summary report.

Performance Period: March 2016 - September 2017

\subsection{WHOLE CORE THERMO-MECHANICAL FUEL PERFORMANCE}

In this task the performance of FCM fuel particles, pellets, and pins in existing LWRs will be assessed. Specifically during NO and anticipated operating occurrences (AOO) conditions using best estimate values and with peaking factors from the whole core neutronic analysis completed in Task III-1.

Work Tasks:

Improve material models and engineering-scale models for FCM fuel as needed. Using input conditions obtained from neutronics and $\mathrm{T} / \mathrm{H}$ calculations, perform failure analyses to assess whether $\mathrm{FCM}$ fuel design limits are likely to be exceeded in LWRs during NO and AOO conditions. If possible, estimate predicted failure probabilities for fuel particles and pins; compare pin failure probabilities to reference $\mathrm{UO}_{2} /$ Zircaloy fuel pins. In order to cover potentially limiting design basis accidents (DBAs), perform analyses to support an assessment of behavior and performance during a reactivity-initiated accident (RIA).

\section{Output:}

An improved assessment of whether fuel cladding design limits are likely to be exceeded for FCM fuel pins in LWRs during NO and AOO conditions.

Milestone 2.3.1: Summarize all findings into a written report and incorporate into later Analysis Phase III summary report.

Performance Period: August 2018 - September 2019 


\section{SYSTEM LEVEL ANALYSIS}

Successful deployment of FCM fuel in LWRs requires system analysis incorporating separate and integrated analyses for multiple disciplines and operational conditions. The transition from the existing LWR $\mathrm{UO}_{2} /$ Zircaloy fuel/cladding system to an ATF fuel/cladding concept will include multiple stages as the core design moves through successive phases: an equilibrium $\mathrm{UO}_{2} /$ Zircaloy core, a mixed transition core containing $\mathrm{UO}_{2} /$ Zircaloy and ATF (e.g., FCM/FeCrAl) assemblies, an initial all-ATF core, and an equilibrium all-ATF core. This document focuses primarily on analyses of an equilibrium all-ATF FCMfueled reactor core configuration that will be performed during the material development phase (Section 3.1). The predicted performance of the equilibrium ATF core and fuel design will dictate whether the performance of the fuel and system are attractive enough for utilities to adopt the FCM ATF fuel concept. Multiple cladding materials options potentially exist for FCM fuel pellets, including FeCrAl and SiC-based composites; no single cladding material has been selected as a reference material at this point, but the choice of cladding material will affect system analysis. For the purposes of this document, it should be noted that unless otherwise stated all analyses are assumed to model UN fuel kernels with natural (non-enriched) nitrogen.

The analyses span disciplines including reactor physics (neutronics), $\mathrm{T} / \mathrm{H}$, thermo-mechanical fuel performance (FP), and core components and chemical interactions $(\mathrm{CC}+\mathrm{CI})$ including severe accident (SA) analysis and coolant chemistry. All of these analyses will be integrated to establish a baseline fuel rod and assembly design that satisfies general constraints for a "one-to-one" replacement fuel assembly (boundary conditions) and seeks to achieve certain objectives (performance metrics).

Successful ATF concepts must maintain the performance achieved by existing fuels during normal steady-state operation and provide enhanced safety margin over existing fuels with respect to design basis accidents (DBAs) and beyond design basis accidents (BDBAs). In addition, a new cladding must meet regulatory licensing criteria for DBAs. DBAs and BDBAs involve the entire core, primary system, emergency core cooling system, as well as other engineered systems and barriers. The accidents also involve the integral effects of various phenomena. System-level analysis of DBAs and BDBAs is required to demonstrate the gains afforded by ATF concepts.

Deployment of FCM fuel as an ATF concept significantly departs from the requirements and constraints of a "drop in" replacement fuel assembly including conforming to existing fuel rod and assembly/bundle geometries, using $\mathrm{UO}_{2}$ fuel pellets, maintaining internal assembly/bundle configurations and layouts, and maintaining the same core thermal power. For FCM fuel, standard LWR fuel rod dimensions (e.g., from a Westinghouse $17 \times 17$ PWR fuel assembly or GE14 Boiling Water Reactor (BWR) fuel bundle) may be modified, including fuel rod outer diameter and lattice configuration (e.g., shifting from a $17 \times 17$ PWR lattice to a $13 \times 13$ lattice using thicker pins), in order to maximize heavy metal loading. However, these changes need to stay within the same assembly/bundle footprint to enable deployment in existing LWRs and minimize impacts on thermal-hydraulic behavior and performance. In addition, shifting the lattice arrangement in FCM fuel may require significant additional work to identify a new control rod cluster design/layout and demonstrate its effectiveness.

Objectives to be considered performance metrics and therefore chosen to yield an attractive baseline design include operational factors such as:

- maintaining the same cycle length (in units of effective full power days [EFPD]) as could be achieved by using $\mathrm{UO}_{2} /$ Zircaloy in a given system,

- maintaining the same number of reload batches used for core refueling, and 
- maintaining the uranium enrichment in all fuel (including peak enrichment zones) below the existing 5\% limit in place for many fuel cycle facilities and activities (e.g., storage and transportation), or if enrichments above 5\% are needed demonstrate why this might be acceptable for various facilities and activities (e.g., an enrichment above 5\% in a particle-based fuel could have lower U-235 mass per total fuel assembly volume and thus potentially satisfy criticality safety requirements).

It should be noted that the items identified above are objectives, not requirements; some designs could, for example, require reduced cycle lengths or increased enrichment levels but still prove to be an overall attractive baseline design and be acceptable to vendors and utilities. These tradeoffs would have to be investigated and justified.

As discussed above, the performance of the ATF design must be evaluated over a range of conditions and events. The categorization of the classification of an event during the operation of a nuclear reactor is primarily based on the frequency of the event occurring, and the identification of the radiological damage as a frequency of the occurrence. The details of the approach are not defined here, but in general the approach includes the identification of possible (more than credible) events (internal and external) that challenge the fission product barriers under all operational conditions. These include:

- Identifying the barrier failure mechanisms in the fuel, clad, reactor vessel, and containment

- Identifying the physical process(es) driving the failure (e.g., thermal overpower such as rod ejection, fast boron dilution, flow reduction, heat increase, etc.)

- Identifying the physical process driving the failure (e.g., Crack growth, overpressure)

- Identifying scenarios for the groups of failures, and postulate the initiating events driving these scenarios (e.g., increase in steam flow, or decrease in feed water temperature, etc.)

The categorization is then based on the frequency of the initiating event, determining the bounding assumptions on the postulated initiating event, and the consequences. There are a number of applicable technical standards, regulations and guides that outline this in detail such as ANSI/ANS 51.1, NRC 10 CFR 50, and the NUREG 0800 standard review plan. A summary of the categories from different bodies can be seen below: 


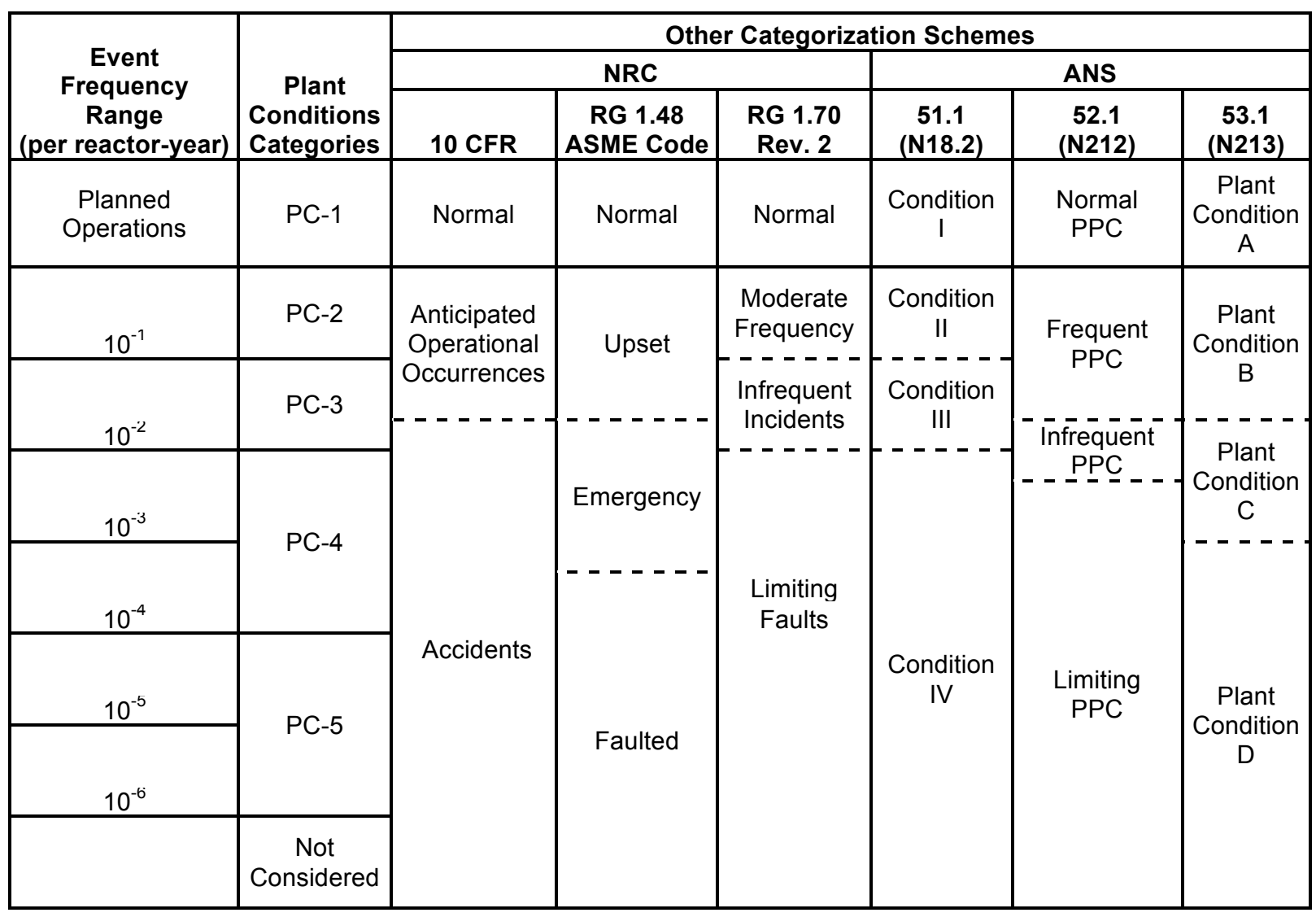

Therefore, in order to define the scope of the design and analysis work required for ATF systems assessment, the analysis scope outlined below has been described based on these different event classifications, in particular:

- Normal Operation (NO) - examples: startup, shutdown (hot and cold), refueling, hot standby, power operation (including load follow)

- Anticipated Operating Occurrences (AOOs), arrested by the protection systems - examples: inadvertent control rod withdrawal, partial loss of reactor coolant flow, control rod drop, reactor coolant system depressurization, reactor or turbine trip, chemical shim dilution

- Design Basis Accidents (DBAs) - examples: small-break loss of coolant accident (SB-LOCA), single reactor coolant pump locked rotor, control rod ejection

- Beyond Design Basis Accidents (BDBAs) - examples: loss of coolant accident without safety injection (LOCA without SI), loss of coolant accident with station blackout (LOCA with station black-out [SBO])

With each of the phases of work outlined below, a more rigorous and involved set of analyses are considered as the technology options are evaluated, screened and developed. These analyses types are similar to the fundamental design and licensing calculational sequence that would form part of an eventual submittal by the licensee to insert a lead test rod (LTR) for irradiation in a commercial LWR; however, the purpose of this Technology Implementation Plan (TIP) and therefore the analysis program outlined below in Section 3.1 is not the design and licensing work itself but rather to provide confidence in the FCM ATF concept before significant investments of time and money are made for licensing efforts. The results from these analyses should be documented and shared with the licensee to support their licensing analyses, but LTR analysis would need to be performed separately by the reactor licensee in 
conjunction with the vendor using approved methodologies and codes, and submitted to the regulatory commission (NRC) by the licensee of the reactor in question.

Future work not described below should also include the previously mentioned transition analyses moving from an equilibrium $\mathrm{UO}_{2}$ /Zircaloy core to a mixed transition core containing $\mathrm{UO}_{2} /$ Zircaloy and ATF assemblies, then an initial all-ATF core, and finally an equilibrium all-ATF core. Lastly, it must be noted that all of the analyses described below focus on reactor operation of FCM fuel assemblies; issues related to front end (e.g., mining, enrichment, and fabrication), backend (e.g., storage, transportation, reprocessing, and/or disposal), and licensing (e.g., enrichments above 5\% and materials not in current regulations such as coated fuel particles and nano-infiltration and transient eutectic-phase [NITE] SiC) would need to be analyzed at some point as well in order to encompass the entire nuclear fuel cycle.

\subsection{ATF ANALYSIS DURING THE MATERIAL DEVELOPMENT PHASE}

The analysis work for the material development phase must cover multiple disciplines and plant conditions, as described above. These analysis efforts have been divided into three phases to assist in planning and work control, to help guide the material development process, and overall evaluation of the ATF concept:

- Analysis Phase I: Feasibility - Early feasibility assessment of steady-state neutronics performance and whether or not ATF concept brings benefits for SA scenario(s). This phase supports advancing the concept from a technology readiness level (TRL) of 2 to 3.

- Analysis Phase II: Proof of Principle - Extended analyses including other disciplines and behaviors/performance of interest. This will support extending the ATF concept from a TRL of 3 to 4.

- Analysis Phase III: Development - With the concept firmly established and determined as reasonable during Analysis Phases I and II, this phase greatly expands the level of detail and applicability for system analyses and further integrates the different disciplines. This phase aides taking the ATF concept from a TRL of 4 to 5, and sets the stage for an LTR analysis effort (see Section 3.2).

The flow diagram below offers a visual summary of the analyses envisioned to be necessary. A Gantt chart should be developed to show the sequencing and effort levels needed for these analyses. It should be noted that some analyses are BE while others include or rely upon actual peaking factors (PFs) calculated explicitly in the latter analysis phases. Estimated effort levels on an initial Gantt chart should assume high-performing national lab research and development (R\&D) staff performing the activities; the estimates could increase significantly if less-experienced personnel perform the work.

It is also important to note that all new analyses are assumed to start no earlier than FY16 Q1 because no additional analysis work is planned right now for FCM fuel in existing LWRs during FY15. Starting analysis in FY16 Q1 would require such work being put into the planning process for FY16 and properly funded; if that window is missed, the Advanced Fuels Campaign (AFC) could likely redirect some work efforts to FCM fuel if desired, or the analysis window would be delayed to start date of FY17 Q1. 


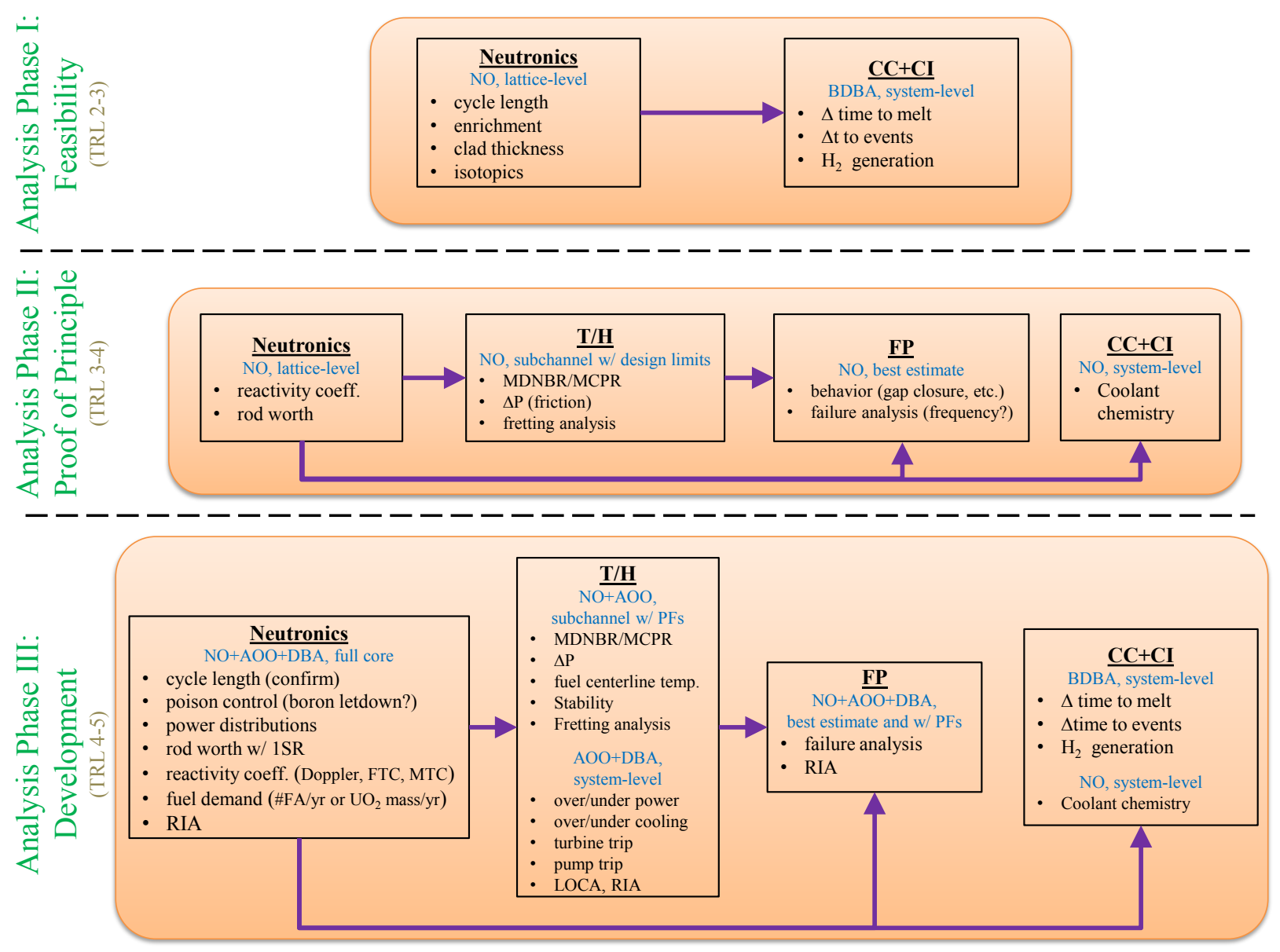

\subsubsection{Analysis Phase I: Feasibility Assessment}

\subsubsection{Neutronics Phase I}

\section{Objective:}

Assess basic feasibility of FCM fuel pins in existing LWRs during steady-state normal operations using lattice-level neutronics calculations. FCM fuel offers a far greater number of degrees of freedom for design studies than many other ATF concepts: several different possible cladding materials and thicknesses should be assessed, multiple lattice configuration options should be analyzed, different fuel kernel materials could be investigated, and full ranges of possible particle packing fractions and kernel diameters should be explored. These analyses balance the competing desires for speed and quality by minimizing labor effort and calendar time required to provide a reasonable first-order assessment of the impact on neutronic performance of switching to an ATF fuel and/or cladding concept in existing LWRs. In addition to providing a first-order feasibility assessment, these analyses establish a reference FCM ATF pin and assembly lattice design.

Work Tasks:

Lattice-level reactor physics calculations will be performed to identify what parameter combinations (uranium enrichment, fuel kernel material and diameter, particle packing fraction, and cladding material and thickness) are required to match the operational cycle length (in EFPD) obtained from reference Zircaloy $/ \mathrm{UO}_{2}$ fuel calculations. 
Much of this work has already been completed. Several different research efforts have performed pinlevel and lattice-level FCM calculations using a variety of fuel kernel materials, cladding materials, and lattice configurations [6-9]. Though these references do not all agree on assumptions, approximations, or precise results, the general trends available from existing analysis should be sufficient to satisfy the vast majority of work needed for this task. Any remaining calculations needed to explore or document design space should be performed and then the body of work should be summarized in a single document.

Output:

Estimated ranges for required or desired clad material and thickness, uranium enrichments, kernel material and diameter, particle packing fraction, and a first-order assessment of overall neutronic feasibility of the FCM ATF concept. These ranges should provide feedback for material technology development (e.g., feedback on clad composition and thickness range). This output will also be used for system-level severe accident analyses being performed in Analysis Phase I.

Milestone 3.1.1.1.1: Provide and summarize suggested fuel design parameters in a written report to help guide material technology development and as input conditions to Phase I SA analysis calculations described below in Section 3.1.1.2. Incorporate all findings into later Analysis Phase I summary report.

Performance Period: August 2012 - February 2016

\subsubsection{Core component mechanical and chemical interaction Phase I}

\section{Objective:}

Assess basic feasibility of FCM fuel assemblies improving system-level performance during SAs by providing increased coping time, decreased gas generation, decreased and delayed releases of radionuclides, and other improvements.

Work Tasks:

Modify fuel properties in SA analysis codes (e.g., MELCOR 1.8.6) to reflect FCM ATF concept. Perform system-level SA analyses for one or more possible SA progression scenarios for LWRs (e.g., PWR or BWR with LOCA and SBO) using FCM fuel assemblies. Estimate potential gains in increased coping time, decreased gas generation, decreased and delayed releases of radionuclides, and other improvements. Other parameters calculated would include the change in time before other events (e.g., lower head failure in a BWR), hydrogen gas $\left(\mathrm{H}_{2}\right)$ generation as a function of time during the SA scenario(s), and the amount and timing of radionuclide release from the fuel, from the primary system, and from containment.

\section{Output:}

These modeling efforts and analyses will provide estimated gains in system-level performance during SA scenarios for LWRs using FCM assemblies, as well as a first-order assessment of the FCM ATF concept in terms of system-level $\mathrm{CC}+\mathrm{CI}$ performance during BDBAs.

Milestone 3.1.1.2.1: Estimate gains in SA performance, summarize all findings into a written report, and incorporate into Analysis Phase I summary report.

Performance Period: February 2016 - September 2016 


\subsubsection{Analysis Phase II: Proof of Principle}

\subsubsection{Neutronics Phase II}

Objective:

Extend the Analysis Phase I neutronics work by continuing lattice-level steady-state normal operations calculations of FCM fuel assemblies in existing LWRs to assess reactivity coefficients and lattice reactivity control rod worth. These analyses investigate more detailed behaviors than in Analysis Phase I and help set the foundation for full-core calculations in Analysis Phase III.

Work Tasks:

Lattice-level reactor physics calculations of normal operations will be continued from Analysis Phase I work to assess impacts on reactivity coefficients and lattice reactivity control rod worth. Reactivity coefficients to be investigated include moderator temperature coefficient (MTC), fuel temperature coefficient (FTC), Doppler coefficient, void coefficient, and boron coefficient. Lattice reactivity control rod worth provides a first-order estimate of what impact the change in the fuel/cladding system may have on eventual control rod worth calculations performed during full-core analyses in Analysis Phase III, and prepares the ground for any subsequent design changes that may be needed (e.g., use of higher worth control rods). Analyses should update estimated ranges for cladding thickness and uranium enrichment levels needed to achieve desirable cycle lengths as well as firmly establish a reference lattice design and layout, choosing not only the number of pins in the lattice but also any internal layouts needed such as burnable poison patterns and which rod positions will contain guide tubes or instrumentation tubes. During this phase and task, researchers should also work to identify any additional analyses or assessments that will be needed to address previously unidentified issues introduced by switching the fuel type from $\mathrm{UO}_{2}$ to $\mathrm{FCM}$.

\section{Output:}

Update estimated ranges for required or desired clad thicknesses and uranium enrichments, burnable poison loading design, lattice arrangement including the number of pins and which rod positions will contain guide tubes or instrumentation tubes, as well as estimated reactivity coefficients. These ranges may provide additional feedback for material technology development (e.g., feedback on clad composition and thickness range or even fabrication processes needed). This output will also be used for fuel performance analyses in Analysis Phase II and provide useful understanding for full-core neutronics calculations in Analysis Phase III.

Milestone 3.1.2.1.1: Estimate desired ranges of fuel design parameters in a written report to provide feedback to material technology development and input conditions for fuel performance analyses in Analysis Phase II and Analysis Phase III. Summarize all findings and incorporate them into later Analysis Phase II summary report.

Performance Period: August 2016 - March 2017

\subsubsection{Thermal hydraulics Phase II}

\section{Subchannel Subtask}

Objective:

Proof of principle confirmation of thermal performance of assembly design (at assembly level).

Work Tasks:

Subchannel $\mathrm{T} / \mathrm{H}$ analyses will be performed to analyze key thermal performance measures such as minimum departure from nucleate boiling ratio (MDNBR), minimum critical power ratio (MCPR), fuel 
centerline temperature (FCT), and key hydraulic performance measures (pressure drop, axial forces) for FCM fuel assemblies. It must be ensured that all values are within acceptable design limits, in particular because the lattice dimensions may change from the standard LWR fuels.

Output:

Acceptance and/or refinement of lattice design. Some of this output will be used to establish input conditions for Analysis Phase II fuel performance work and cross-flow rates for Grid-to-Rod Fretting (GTRF) analyses.

Milestone3.1.2.2.1: Write a report documenting the acceptability of the proposed FCM assembly design from Analysis Phase I neutronics analysis results or provide suggested or required changes. Summarize all findings and them incorporate into later Analysis Phase II summary report.

Performance Period: August 2016 - December 2016

\section{Grid-to-Rod Fretting Subtask}

Objective:

Proof of principle investigation of GTRF potential of FCM assemblies. These analyses need not be exhaustive or overly complicated but they should provide useful feedback.

Work Tasks:

Modal analysis will be performed on segments of the baseline FCM ATF concept. Potential excitation frequencies and displacements will be evaluated. The analyses, coupled with material properties, will provide a comparison against the baseline Zircaloy cladding. Potential move away from standard $\mathrm{Zr}$ materials and fuel pin dimensions will necessitate the need for this analysis.

\section{Output:}

Assess the acceptability of the proposed lattice design (e.g., grid spacing, fuel pin diameter, and pin pitch) and material properties (e.g., cladding thickness or stiffness). Suggest any refinements that are needed or could be beneficial in either of these areas.

Milestone 3.1.2.2.2: Assess the proposed lattice design and material properties and identify any suggested or required improvements to them in a written report. Summarize all findings and incorporate them into later Analysis Phase II summary report.

Performance Period: September 2016 - September 2017

\subsubsection{Thermomechanical fuel performance Phase II}

See Section 2.2.

\subsubsection{Core component mechanical and chemical interaction Phase II}

\section{System-level BDBA Subtask}

Objective:

Quantify gains provided by FCM ATF concept, specifically related to radionuclide release timing and quantity.

Work Tasks:

Analyze key severe accident metrics (e.g., margin in time to key accident stages [melting, relocating, loss of primary containment, off-site release], combustible gas generation, and radionuclide release [timing, 
quantity]). Analysis will be performed at a whole system-level to include the integral effects of multiple systems and phenomena. The analysis will focus on radionuclide release/retention. Specifically, effort will be focused on accurately modeling the radionuclide release characteristics of FCM fuel and in determining the timing and quantity of releases to the environment. The analyses will include updated radionuclide inventory, decay heat, and geometry insight from the other tasks.

Output:

Quantified gains provided by FCM ATF concept. Identification of material property (radionuclide release) data gaps.

Milestone 3.1.2.4.1: Write a report quantifying FP retention gains provided by the FCM ATF concept and identify material property knowledge data gaps. Summarize all findings into a written report and incorporate them into later Analysis Phase II summary report.

Performance Period: August 2016 - August 2017

\section{Coolant Chemistry Subtask}

Objective:

Estimate the level of impact of change in cladding and dimensions on coolant chemistry issues introduced by using FCM fuel assemblies instead of $\mathrm{UO}_{2} /$ Zircaloy in existing LWRs under NO conditions at the system-level. Establish proof of principle level confirmation that no insurmountable coolant chemistry issues exist.

Work Tasks:

Perform preliminary coolant chemistry assessments and screening analyses to estimate the first-order impacts of switching from $\mathrm{UO}_{2} /$ Zircaloy assemblies to $\mathrm{FCM}$ fuel assemblies with several possible cladding material options (including $\mathrm{FeCrAl}$ and $\mathrm{SiC}$ ) for existing LWRs in NO conditions. Effects such as corrosion, and resulting required changes in coolant chemistry will be evaluated.

\section{Output:}

Proof of principle assessment of the acceptability of coolant chemistry performance of FCM fuel assemblies in LWR water chemistries and environments and recommendations on potential changes required to coolant chemistry. Corrosion correlations and associated data that are unavailable will be highlighted, and a path forward identified. Parametric analysis will be completed in the absence of critical material properties.

Milestone 3.1.2.4.2: Write a report identifying key coolant chemistry issues affected by the change in cladding/fuel, including identification of the material property and modeling data that is currently unavailable. Any early indication of possible changes needed to the coolant chemistry will be identified and highlighted. Summarize all findings into a written report and incorporate into later Analysis Phase II summary report.

Performance Period: August 2016 - December 2016 


\subsubsection{Analysis Phase III: Development}

\subsubsection{Neutronics Phase III}

Objective:

Confirm findings from Analysis Phases I and II and examine neutronic performance of an LWR core using FCM fuel assemblies in much greater detail than previously accomplished using full-core neutronics analyses for existing LWRs under NO, AOO, and DBA conditions.

Work Tasks:

Perform full-core neutronics analyses of LWRs under NO, AOO, and DBA conditions to accomplish multiple objectives including: confirm desirable cycle length for baseline values of clad thickness and uranium enrichment; investigate excess reactivity and power shaping control using poisons including soluble boron in the coolant (i.e., boron letdown curves) and local poison loading such as Integral Fuel Burnable Absorbers (IFBAs), Wet Annular Burnable Absorbers (WABAs), distributed poison in the FCM matrix, or poison loaded into coated fuel particle or separate coated point particles. Determine the impact of FCM fuel assemblies on assembly-level and pin-level power distributions. Examine the control rod bank worth in the core with one stuck rod assembly. Calculate full-core reactivity coefficients (e.g., MTC and FTC). Estimate fuel demand in terms of the number of fresh fuel assemblies needed per year and/or the feed uranium mass needed per year. In order to cover potentially limiting DBAs, perform analyses to support an assessment of behavior and performance during a RIA.

\section{Output:}

Results will include confirmed baseline values for clad thickness, uranium enrichments, lattice configuration including control rod cluster layout, particle design (materials and geometry of particles to be used), particle packing fractions in FCM matrix, and predicted cycle length. Power distributions will be produced for use throughout all analyses in Analysis Phase III work. Reactivity coefficients, rod worth, cycle length and fuel demand will help support economic and subsequent analyses (e.g., Section $3.2)$.

Milestone 3.1.3.1.1: Confirm baseline fuel lattice design parameters and provide key physics design products (e.g., power distributions, reactivity coefficients, cycle length, power histories) that support later work in Analysis Phase III, economic analysis, and LTR analyses described in Section 3.2. Summarize all findings into a written report and incorporate into later Analysis Phase II summary report.

Performance Period: August 2017 - September 2018

\subsubsection{Thermal hydraulics Phase III}

\section{Subchannel Subtask}

As part of this subtask assembly-level analysis of thermal performance will be performed on FCM core.

Work Tasks:

Analyze key thermal performance measures (MDNBR/MCPR, FCT, etc.) and key hydraulic performance measures (pressure drop, axial forces) for an assembly employing FCM fuel over a range of NO, AOO, and DBAs. Ensure values are within acceptable limits.

Output:

Thermal performance history for fuel performance and reactivity calculations. 
Milestone 3.1.3.2.1: Assess subchannel-level thermal performance of FCM-fueled LWR core over a range of core operating conditions and provide required thermal-hydraulic parameters to follow-on fuel performance and reactivity analyses. Summarize all findings into a written report and incorporate into later Analysis Phase II summary report.

Performance Period: August 2017 - November 2018

\section{System-level Subtask}

The objective of this subtask is to expand on system-level analysis of thermal performance during NO, AOO, DBAs.

Work Tasks:

Add FCM as a fuel independent material in systems code. Also add new cladding material(s) as needed with the best available properties and oxidation characteristics into systems code. Analyze the LWR design, with respect to key thermal performance criteria, for NO as well as AOO and DBA transients. The analysis will assess the concept in relation to the existing reactor systems and equipment set points. The gains in thermal performance metrics (time to fuel failure during DBAs) will be quantified.

Output:

System level thermal performance for fuel performance and criticality calculations.

Milestone 3.1.3.2.2: Write a report assessing system-level thermal performance of an FCM-fueled LWR during a range of operating conditions. Summarize all findings into a written report and incorporate into later Analysis Phase II summary report.

Performance Period: August 2017 - March 2018

\section{Grid-to-Rod Fretting Subtask}

The purpose of this subtask is to expand upon the work in Analysis Phase II and assess whether FCM fuel pins are likely to exhibit significantly different GTRF behavior than reference $\mathrm{UO}_{2} /$ Zircaloy fuel pins.

Work Tasks:

Perform simple GTRF and wear analyses for NO and AOO conditions with power peaking factors if needed. Compare results for FCM fuel pins/assemblies to the results from reference $\mathrm{UO}_{2} /$ Zircaloy fuel assemblies. This work expands upon GTRF assessment from Analysis Phase II (Section 5.1.2.2) by using updated assumptions for FCM fuel designs as well as more detailed results from Analysis Phase III neutronics calculations (Section 3.1.3.1).

Output:

Assess possible GTRF issues in FCM fuel pins/assemblies to ensure proper fuel performance. Suggest any lattice design refinements needed or show the acceptability of the existing proposed design.

Milestone 3.1.3.2.3: Provide an assessment of any expected GTRF issues in the proposed FCM fuel assembly design, documenting its acceptability or suggested refininements. Summarize all findings into a written report and incorporate into later Analysis Phase II summary report.

Performance Period: September 2018 - September 2019

\section{Stability Subtask (for BWRs)}

The objective of this subtask is to expand on the stability analysis for BWR NO, AOOs, and DBAs. 
Work Tasks:

Specific for BWRs, perform stability analysis to assess stability regimes for assembly design.

Output:

Confirmation/design revision of FCM ATF assembly design.

Milestone 3.1.3.2.4: Assess stability performance of FCM-fueled BWRs and suggest any required design changes. Summarize all findings into a written report and incorporate into later Analysis Phase II summary report.

Performance Period: November 2017 - September 2019

\subsubsection{Thermomechanical Fuel Performance Phase III}

See Sections 2.2 and 2.3.

\subsubsection{Core Component and Chemical Interaction Phase III}

\section{System-level BDBA Subtask}

As part of this subtask the relative gains attributable to the FCM ATF concept will be quantified, using explicit values/analyses from the whole core neutronics and thermo-mechanical fuel performance completed in the earlier phases.

Work Tasks:

Analyze key severe accident metrics including margin in time to key accident stages (melting, relocating, loss of primary containment, off-site release), combustible gas generation, and radionuclide release (timing, quantity). Analysis will be performed at a whole system-level to include the integral effects of multiple systems and phenomena. The analysis will include multiple severe accident scenarios representative of the potential spectrum. The analysis should identify any differences/benefits in severe accident mitigation actions that may require further attention.

Output:

Quantified gains provided by FCM ATF concept across a broad range of possible SA scenarios and updated severe accident mitigation guidance (SAMG) if applicable.

Milestone 3.1.3.4.1: Quantify SA performance gains offered by FCM fuel in LWRs in a written report and suggest possible updated SA mitigation guidance. Summarize all findings and incorporate into later Analysis Phase III summary report.

Performance Period: December 2018 - September 2019

\section{Coolant Chemistry Subtask}

Objective:

Update the coolant chemistry tools, models, and assessment, using explicit assembly and/or pin power histories from the whole core neutronics and $\mathrm{T} / \mathrm{H}$ analyses, building on the needs identified in the earlier phases.

Work Tasks:

Perform coolant chemistry calculations and screening analyses using explicit power histories to estimate the impacts of switching from $\mathrm{UO}_{2} /$ Zircaloy to FCM fuel with several possible cladding material options for existing LWRs in NO conditions. This is likely to include the need to develop new models for the 
coolant chemistry codes, and identification of new corrosion phenomena and data. New coolant chemistry regimes to avoid operational issues will also need to be confirmed.

Output:

Demonstrate acceptable proof of principle coolant chemistry performance of FCM fuel assemblies in LWR water chemistries and environments.

Milestone 3.1.3.4.2: Summarize all findings into a written report and incorporate into later Analysis Phase III summary report.

Performance Period: January 2019 - September 2019

\subsection{LTR ANALYSIS}

As stated previously, the purpose of this TIP and therefore the analysis program outlined in Section 5 is not design and licensing work to support LTR insertion into a commercial LWR in the US but rather to provide confidence in the FCM ATF concept before significant investments of time and money are made for licensing efforts. The results from these analyses should be documented and shared with the licensee to support their licensing analyses, but LTR analysis would need to be performed separately by the reactor licensee in conjunction with the vendor using approved methodologies and codes and submitted to the NRC by the licensee of the reactor in question.

Extensive analysis would likely be needed to support LTR testing given the likely introduction of new fuel and cladding materials, a new fuel form (coated fuel particles in a matrix), and a likely in lattice design and configuration. 


\section{FABRICATION AND QUALIFICATION}

The FCM fuel consists of TRISO particles embedded in an impervious silicon carbide matrix. The TRISO fabrication and resulting fuel will be very similar in structure to that developed and perfected under the DOE AGR Program [10]. However, due to the need for higher fissile material loading in the fuel, uranium nitride kernels are under development [11]. Moreover, the TRISO constituent layers will be modified to maximize uranium content while maintaining performance. While there are a myriad types and processes by which $\mathrm{SiC}$ ceramics can be achieved, most are not irradiation stable and are arrived at through process temperatures and pressures higher than what can be tolerated by the TRISO fuel particles. The key process enabling the FCM fuel fabrication is a variant on liquid phase sintering of nanopowder SiC in which the processing temperature and pressure are significantly reduced through the use of limited additions of rare earth oxides. This process is similar to the NITE SiC production technology [12]. Details of the fabrication and characterization of FCM fuel pellets have been underway since 2012 using this NITE processing technology [13-15]. Currently, process optimization, resulting properties, development of high-density kernels, and the ability to scale to resulting product to mass production are the focus of the FCM fabrication and QA program.

\subsection{BASE FUEL FABRICATION AND PROPERTIES}

\subsubsection{Uranium Nitride Kernel Development}

Objective:

Develop a well-understood and codified process for production of dense uranium nitride kernels. The kernels shall be crack and defect free, spherical, and produced in a considerable batch size $(\sim 50 \mathrm{~g}$ or bigger) so that they could be utilized during coating process and final fuel form fabrication. Once the process is technically understood it will be scaled for production of fuel kernels for irradiation.

Milestone 4.1.1.1: Final report on optimized UN kernel production for LWR TRISO application. Performance Period: May 2014 - July 2015

Milestone 4.1.1.2: Production of high-density UN kernels for FCM-LWR irradiation studies. Performance Period: June 2015 - January 2016

\subsubsection{Coating and Matrix Consolidation}

Objective:

Develop a codified and optimized process for coating layer deposition (i.e. carbon buffer, pyrocarbon, and chemical vapor deposited [CVD]-SiC) on UN kernels based on the previous AGR experience. Consistent with the past experience, the fluidized bed chemical vapor deposition (FBCVD) technique will be utilized for this effort. Technique development and optimization is necessary for coating of the UN kernels. These changes in processing conditions were required to maintain acceptable coating properties due to physical property and dimensional differences between the UCO (mixed uranium oxide-carbide kernels used in AGR program) and UN kernels. For instance, early indications show significant increases $(\sim 50 \%)$ in gas flows are required to fluidize the high density UN kernels compared to the UCO kernels previously used.

Milestone 4.1.2.1: Issue progress report on UN kernel coating development and deposition activities. Performance Period: May 2014 - August 2015

The programmatic objective of this activity is the production of final microencapsulated TRISO particles that are qualified for eventual compaction in FCM matrix and irradiation. This implies that these particles 
are the most suitable for the LWR application (i.e. most suitable for the temperature, power density, and burnup range as specified in [2]).

Milestone4.1.2.2: Issue report on Compaction Activities Leading to FCM-LWR Fuel Production. Performance Period: May 2014 - January 2016

\subsection{SCALE-UP/COMMERCIALIZATION STUDIES}

The current FCM production route utilizes hot pressing of a nanopowder mixture of SiC with selected rare earth oxides and the TRISO fuel particles. This process produces single fuel pellet and for this reason is not desirable for mass production. As the ability to commercially use this fuel is the ultimate goal of this work a parallel task to develop a process amenable to mass-production of fuel is called for. Some of the potential routes could be batch scale hot isostatic pressing (HIP), and field-assisted sintering (FAS) such as spark plasma sintering (SPS).

Objective:

The objective of this work is to explore advanced methods of hot compaction of FCM fuel compacts that offer high quantity and reliable yields.

Milestone4.2.1: Issue report on FCM mass fabrication/commercialization viability.

Performance Period: October 2015 - September 2016

\subsection{Q/A AND INSPECTION}

ORNL's Quality Assurance (QA) approach for the gamut of technical pursuits comprising the work scope for the first irradiation batch of FCM is described in Document \#QAP-ORNL-FCT-01 entitled Quality Assurance Plan and Interface Document for Fuel Cycle Technology Research and Development Activities Conducted at Oak Ridge National Laboratory (hereafter referred to as the QAP). The QAP is established, maintained, and executed in accordance with the applicable criteria of the ORNL Quality Assurance Program Description, and is an enabling document for quality-related work associated with FCT activities to be conducted at ORNL or for ORNL by any subcontracted organizations. The ORNL QA Program addresses the requirements contained in DOE Order 414.1D and in 10CFR830, Subpart A and is applied on a graded basis to all work activities at the site. ORNL's QA Program also provides the flexibility and authorization to develop activity-specific programs to meet national and international quality standards and sponsor needs.

ORNL management recognizes that - though FCT activities are conducted as part of an ongoing R\&D effort - successful outcomes represent potential inputs to future design and licensing decisions. The work scope described herein also requires interface with the ATR, a DOE nuclear facility and other materials test reactor operators. Therefore, activities shall be conducted under the QA rigor specified in both the ASME NQA-1-2008 with the NQA-1a-2009 Addendum (Quality Assurance Requirements for Nuclear Facility Applications, hereafter referred to as NQA-1-2008) standard and in the NRC-mandated 10CFR50 Appendix B (Quality Assurance Criteria for Nuclear Power Plants and Fuel Reprocessing Plants). ORNL management's intent is to ensure that this targeted quality program is satisfactory in addressing all FCRD work package milestones assigned to ORNL including those designated Quality Rigor Level 1 as described in the FCT's Quality Assurance Program Document (current version - Revision 2 effective December 20, 2012).

The requirements of the cited quality standards are imposed on a graded basis using the guidance contained in NQA-1-2008, Part IV, Subpart 4.2 (Guidance on Graded Application of Quality Assurance for Nuclear-Related Research and Development). Further, this plan is intended to meld the requirements 
contained in the previously cited national standards with those described in the FCT-issued Quality Assurance Program Document (QAPD). The FCT QAPD represents the highest-tier QA document specific to the FCT mission and applicable to the various work scopes, activities, and tasks funded at DOE-sponsored entities including ORNL.

For FCT activities conducted at ORNL, QA requirements are implemented by line and program management through a combination of the ORNL FCT QAP, associated subordinate QA procedures, and the mandates and requirements conveyed through the ORNL Standards Based Management System (SBMS). The SBMS is ORNL's web-based system for the translation and implementation of applicable laws, orders, and regulatory requirements through the deployment of Laboratory-wide subject areas and procedures. The QAP is intended, in part, to provide the framework for establishing and maintaining a QA program to fulfill the applicable requirements described in the NQA-1-2008 standard and in 10CFR50 Appendix B as they apply to FCT activities. The QAP - plus any additional referenced QA implementing procedures and SBMS documents necessary for conduct of the described work activities constitute the ORNL FCT QA manual. 


\section{NORMAL OPERATION ENVIRONMENTAL EFFECTS}

Normal operation for the FCM fuel as discussed in this document is for a fuel clad within a commercial standard zircaloy or advanced steel clad. It is assumed that the inner-clad environment would be typical helium backfill and that the fuel and clad would be in intimate contact. Primary, normal operation areas to address are therefore the effect of fuel burnup on performance, fast neutron irradiation on fuel properties and performance, and fuel clad interaction. These issues are addressed either prior to, or in parallel to, irradiation experiment providing data of prototypical fuel for qualification.

\subsection{FCM FUEL CONSTITUTIVE PROPERTIES}

Specific properties required for iterative fuel development, fuel modeling, and for informing the integrated fuel irradiation are to be determined through a series of irradiation capsules.

Experimental Requirements:

Irradiation campaign to determine properties and stability of the FCM matrix as a function of dose and (surrogate) particle volume fraction. Irradiation to be carried out in a "rabbit capsule" in the Peripheral Target Tube (PTP) of the HFIR past the point of property saturation for SiC. Capsules to be located just above the reactor mid-plane resulting in a fast neutron flux of $1.01 \times 10^{15} \mathrm{n} / \mathrm{cm}^{2} \mathrm{sec}$. For this position the nominal thermal neutron flux is $2.5 \times 10^{15} \mathrm{n} / \mathrm{cm}^{2} \mathrm{sec}$. An assumed experimental matrix is provided in Table 5.1.1.1.

Data and Post-Irradiation Examination Requirements:

- Dimensional stability of FCM Matrix

- Thermal conductivity compact

- Examination of microencapsulation and FCM interfaces

Milestone 5.1.1: Experimental Matrix and QA Package for FCM-EO series irradiation: Determining Properties and Irradiation Stability of the FCM SiC-based matrix.

Performance Period: June 2012 - August 2014

Milestone 5.1.2: Final Report for FCM-EO series irradiation: Determining Properties and Irradiation Stability of the FCM SiC-based matrix.

Performance Period: June 2012 - December 2015 
Table 5.1.1.1: HFIR FCM Property Investigation Matrix

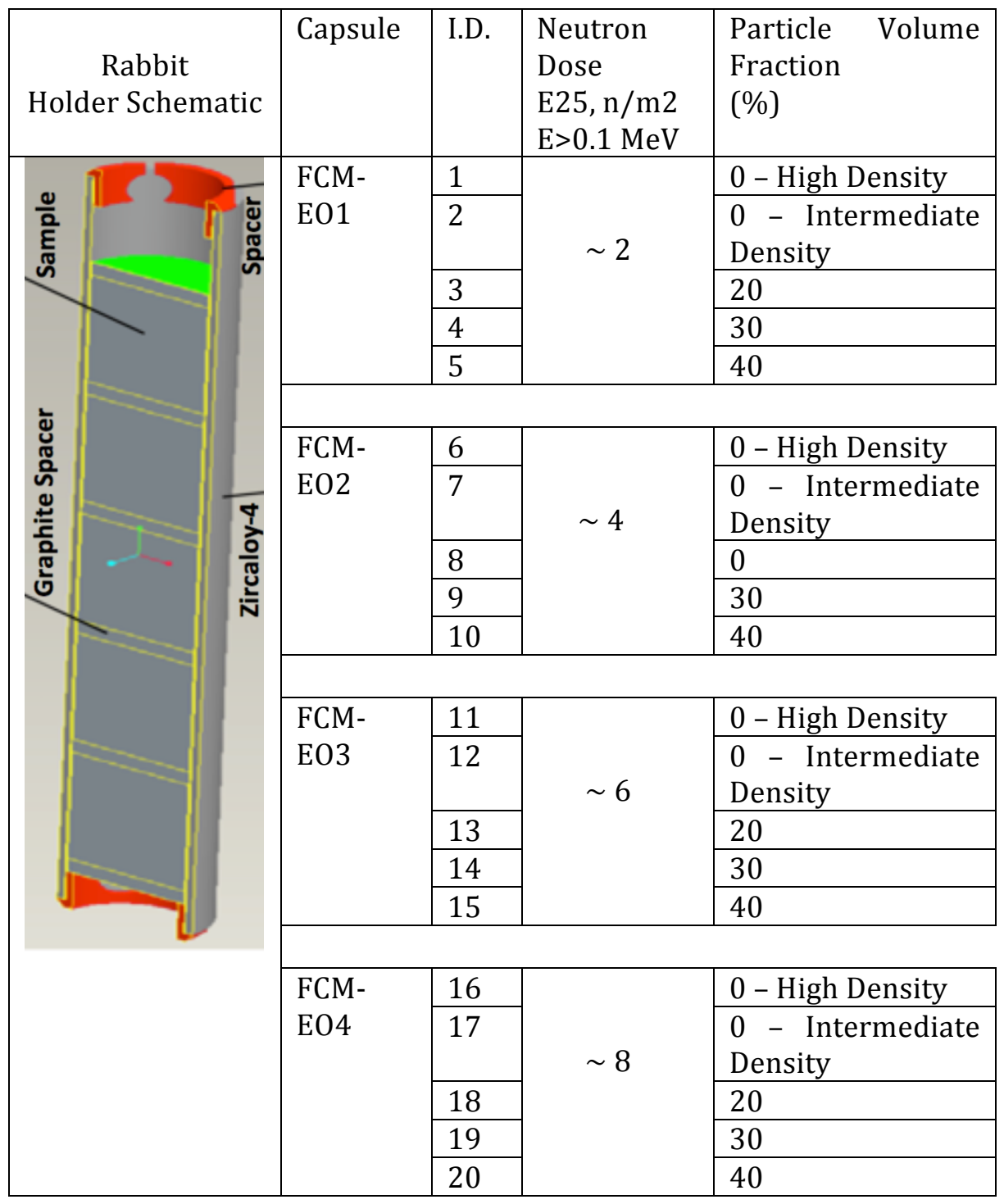

\subsubsection{Surface Heat Flux Limits of FCM-LWR Fuel (FCM-SH Series)}

Experimental Requirements:

In this fuel qualification series FCM fuel will be irradiated in either the ATR, HFIR or Halden reactor facilities to determine the linear heat rate (surface flux capabilites) of the fuel. Fuel will be fabricated with variable kernel diameter to achieve the desired range of surface heat flux in a gas-gap temperaturecontrolled experiment. FCM compaction methodology and resulting matrix microstructure and properties are to be characteristic of the prototype FCM-LTR fuel. Standard drop-in capsule technology will be utilized. Capsule irradiation to be carried out in an inert environment. Fuel burnup and linear heat rate will be in the $50-160 \mathrm{GWd} /$ tonne and $250-425 \mathrm{~W} / \mathrm{cm}$, respectively. A summary of the surface heat flux limit experiment is provided in Table 5.1.1.2. 
Data and Post-Irradiation Examination Requirements:

- Dimensional stability of FCM Matrix

- Thermal conductivity of compact

- Microtomography of fuel compact

- Compressive rupture stress using diametral compression

Milestone 5.1.1.1: Experimental Matrix and QA Package for FCM-SH series irradiation: Determining Surface Heat Flux Limits of the FCM SiC-based matrix.

Performance Period: August 2015 - March 2016

Milestone 5.1.1.2: Interim Fuel Performance Report for FCM-SH series irradiation: Determining Surface Heat Flux Limits of the FCM SiC-based matrix.

Performance Period: June 2016 - June 2017

Milestone 5.1.1.3: Final Fuel Performance Report for FCM-SH series irradiation: Determining Surface Heat Flux Limits of the FCM SiC-based matrix.

Performance Period: June 2016 - December 2018

Table 5.1.1.2: FCM SH Series Property Irradiation Matrix. Linear heat rate assumes a nominal $13 \times 13$ pin geometry






\subsection{FUEL QUALIFICATION FOR NORMAL OPERATING CONDITIONS}

A parallel approach of fuel qualication and LTR or a lead test asemebely (LTA) irradiation will be persued for the FCM fuel whereby a datapackage will be fully prepared for the first LTR residence within the core while the qualification program continues providing fuel qualification to higher burnup (consistent with subsequent fuel shuffling.) Experiments for this fuel qualification series will be instrumented to provide both design data and for data supporting fuel qualification. The fuel specification for the FCM fuel to be irradiated will be identical to that Lead Test Rod insertion.

\subsubsection{Simulated Normal Operation FCM Irradiation Campaign}

Experimental Requirements: Fuel materials for this irradiation will be prototypical FCM materials produced according to the Fuel Fabrication Plan (FFP-FCM-LTR-1) and Quality Assurance Plan (QAPFCT-01) discussed in Section 4.3. Irradiation will be carried out utilizing the an instrumented fuel test at the Halden BWR and possibly the thermosyphon facility at ORNL or the ATR at the Idaho National Laboratory (INL). As a function of burnup performance data will be generated on fuel stack swelling (linear stack and diameter) and fission product release. Identical capsules are to be irradiated in both steady state operation and aggressive operating power swings (load following) to determine what, if any, effect there will be on fission product release or matrix integrity. A standard Halden Reactor 12 pin (upper stack-6 and lower stack-6) is assumed. A series of pins will be irradiated within this IFA to accumulate fluence for the Off-Normal (OffN) testing of Section 6. A summary of the FCM NO Fuel Qualification irradiation series flux limit experiment is provided in Table 5.2.1.1.

\section{Data and Post-Irradiation Examination Requirements:}

- Dimensional stability of FCM Measured In-Situ

- Thermal conductivity inferred by centerline temperature

- Fission product release as a function of burnup and operating scenario.

- Standard post-irradiation examination.

Milestone 5.2.1.1: Experimental Matrix and QA Package for FCM-NO series irradiation. Performance Period: August 2015 - July 2016

Milestone 5.2.1.2: Interim Fuel Performance Report for FCM-NO series irradiation: Determining dimensional stability and fission product release of FCM SiC-based matrix to $70 \mathrm{MWd}$ /tonne.

Performance Period: September 2016 - August 2019

Milestone 5.2.1.3: Final Fuel Performance Report for FCM-NO series irradiation: Determining dimensional stability and fission product release of FCM SiC-based matrix to $160 \mathrm{MWd}$ /tonne.

Performance Period: September 2016 - September 2023 
Table 5.2.1.1: Summary of the FCM NO Fuel Qualification irradiation series to be carried out in the HBWR

\begin{tabular}{|c|c|c|c|c|c|}
\hline & Facility & Capsule & I.D. & $\begin{array}{l}\text { Pin Removal } \\
\text { Burnup } \\
\text { MWd/tonne } \\
\text { And } \\
\text { Operation } \\
\end{array}$ & $\begin{array}{c}\text { Instrumentation } \\
\text { and Capsule } \\
\text { Type }\end{array}$ \\
\hline \multirow{12}{*}{$\begin{array}{l}\text { Bello } \\
\text { End } \\
\text { Support } \\
\text { ferritic }\end{array}$} & \multirow{12}{*}{  } & \multirow{12}{*}{$\begin{array}{l}\text { FCM } \\
\text { NO-A }\end{array}$} & Pin U-1 & $\begin{array}{c}160 \\
\text { steady state }\end{array}$ & $\begin{array}{c}\text { Gas Flow Rig, } \\
\text { Stack Height } \\
\text { Internal Pressure }\end{array}$ \\
\hline & & & Pin U-2 & $\begin{array}{c}160 \\
\text { load follow }\end{array}$ & Pin Diameter \\
\hline & & & Pin U-3 & $\begin{array}{c}125 \\
\text { steady state }\end{array}$ & $\begin{array}{c}\text { Gas Flow Rig, } \\
\text { Stack Height } \\
\text { Internal Pressure }\end{array}$ \\
\hline & & & Pin U-4 & $\begin{array}{c}70 \\
\text { steady state }\end{array}$ & $\begin{array}{c}\text { Centerline Temp } \\
\text { Stack Height } \\
\text { Internal Pressure }\end{array}$ \\
\hline & & & Pin U-5 & $\begin{array}{c}130 \\
\text { steady state }\end{array}$ & $\begin{array}{c}\text { Centerline Temp } \\
\text { Stack Height } \\
\text { Internal Pressure }\end{array}$ \\
\hline & & & Pin U-6 & $\begin{array}{c}160 \\
\text { steady state }\end{array}$ & $\begin{array}{c}\text { Gas Flow Rig } \\
\text { Stack Height } \\
\text { Internal Pressure }\end{array}$ \\
\hline & & & Pin L-1 & $\begin{array}{c}70 \\
\text { steady state }\end{array}$ & $\begin{array}{c}\text { Centerline Temp } \\
\text { Stack Height } \\
\text { Internal Pressure }\end{array}$ \\
\hline & & & Pin L-2 & $\begin{array}{c}130 \\
\text { steady state }\end{array}$ & $\begin{array}{c}\text { Centerline Temp } \\
\text { Stack Height } \\
\text { Internal Pressure }\end{array}$ \\
\hline & & & Pin L-3 & $\begin{array}{c}160 \\
\text { steady state }\end{array}$ & $\begin{array}{c}\text { Gas Flow Rig } \\
\text { Stack Height } \\
\text { Internal Pressure }\end{array}$ \\
\hline & & & Pin L-4 & $\begin{array}{c}70 \\
\text { load follow }\end{array}$ & $\begin{array}{c}\text { Centerline Temp } \\
\text { Stack Height } \\
\text { Internal Pressure }\end{array}$ \\
\hline & & & Pin L-5 & $\begin{array}{c}160 \\
\text { load follow }\end{array}$ & Pin diameter \\
\hline & & & Pin L-6 & $\begin{array}{c}160 \\
\text { steady state }\end{array}$ & $\begin{array}{l}\text { Centerline Temp } \\
\text { Stack Height } \\
\text { Internal Pressure }\end{array}$ \\
\hline
\end{tabular}




\section{OFF-NORMAL ENVIRONMENTAL EFFECTS}

\subsection{CLADDING FAILURE DURING NORMAL OPERATION}

It is plausible that under normal operating conditions, the cladding fails and provides a pathway for the primary coolant to enter the rod. In case of standard fuel, oxidation of $\mathrm{UO}_{2}$ to $\mathrm{U}_{3} \mathrm{O}_{8}$ is not an issue (due to the high local hydrogen activity) and the main concern is the internal oxidation of the cladding and the ensuing secondary hydriding [16]. The extent of radionuclide release from the rod is governed by the inventory at the time and the size of the cladding flaw and the extent of fuel pellet damage. In case of FCM fuel, no direct content between the fissile portion (also the fission-product-bearing region) of the fuel and the coolant is expected; unless severe cracking in the pellets have exposed the kernels. Therefore, the evolution of leaky FCM rods will be governed by interaction between NITE-SiC matrix and the cladding with the superheated steam (primary water flashes into steam once it enters the rod internals) or liquid water.

\subsubsection{Low-Temperature Steam Oxidation of NITE-SiC}

Objective:

To assess the compatibility between the fuel matrix and high-pressure steam at $400-600^{\circ} \mathrm{C}$.

Work Tasks:

High-pressure steam testing of NITE SiC at $400-600^{\circ} \mathrm{C}$ in steam and steam-hydrogen mixtures. Prior data at $800^{\circ} \mathrm{C}$ and higher in these exact environments [17] can also be extrapolated to produce bounding calculations.

Output:

Estimate the extent of fuel degradation during residence time in the core.

Milestone 6.1.1.1: Summarize all findings into a written report along with the rest of the tasks in this section.

Performance Period: October 2015 - December 2016

\subsubsection{High-Pressure Hydrothermal Corrosion of NITE-SiC}

Objective:

Examine the corrosion rate of NITE-SiC in contact with liquid water in a damaged fuel rod.

Work Tasks:

Conduct experiments on high-pressure hydrothermal corrosion of NITE-SiC at elevated temperatures $\left(200-400^{\circ} \mathrm{C}\right)$. The results from autoclave testing on NITE-SiC, already carried out in FY15 can be used for calculating the extent of material degradation under these conditions.

Output:

Estimate the extent of fuel degradation during residence time in the core assuming it's in contact with liquid water.

Milestone 6.1.2.1: Summarize all findings into a written report along with the rest of the tasks in this section.

Performance Period: October 2015 - December 2016 


\subsubsection{Cladding Effects on Fuel Degradation}

Objective:

Once the cladding of choice for FCM fuel has been identified, the integral effects of fuel rod leakage need to be examined.

Work Tasks:

This involves a thermodynamic analysis to determine the component (fuel or cladding) that will undergo oxidation. Following that step is the combined kinetic analysis of fuel degradation.

Output:

Estimate the extent of integral fuel rod degradation during residence time in the core assuming it's in contact with liquid water.

Milestone 6.1.3.1: Summarize all findings into a written report along with the rest of the tasks in this section.

Performance Period: October 2016 - September 2018

\subsection{STEAM OXIDATION}

Under design basis and beyond design basis accident conditions, the fuel pellets become exposed to hightemperature steam environments. The high-temperature steam is generally present at near atmospheric pressures (e.g. under a LB-LOCA or SBO with reactor pressure vessel [RPV] failure). Since multiple barriers for fission product release are inherent to the structure of FCM fuel, it is expected the radionuclide release under these conditions is significant reduced/delayed. To verify this hypothesis, separate and integral tests need to be carried out. Specifically, oxidation of the fuel matrix (NITE-SiC) and TRISO fuel particles need to be studied separately. Afterwards, integral rodlets consisting of fuel pellets inside the optimum cladding need to be tested in these environments, similar to large testing programs carried out in the past for the current fuel system [18].

\subsubsection{Task I: High-Temperature Separate Effects Steam Oxidation of FCM Fuel Constituents}

\section{Objective:}

To assess the oxidation behavior of FCM fuel matrix and TRISO particles in steam at temperatures beyond $1200^{\circ} \mathrm{C}$. These are separate effects tests aiming to provide detailed gas-solid oxidation kinetics. These kinetic parameters can then be subsequently incorporated in severe accident analysis tools.

Work Tasks:

Perform oxidation testing of NITE-SiC and TRISO particles in flowing steam. A significant portion of this work has been completed and reported in the literature under the FCRD Program [19-20].

Output:

Produce report detailing oxidation kinetics for the separate effects tests.

Milestone 6.2.1.1: Summarize all findings into a written report.

Performance Period: October 2015 - December 2016 


\subsubsection{Task II: Integral FCM Fuel Rodlet Testing in High-Temperature Steam}

\section{Objective:}

To assess the oxidation and degradation behavior of integral FCM fuel rodlets (pellets inside the cladding of choice for FCM fuel) in high-temperature steam environments representative of LWR severe accident scenarios.

Work Tasks:

Perform oxidation testing of FCM fuel pellets inside the cladding material of choice (among SiC, coated$\mathrm{SiC}, \mathrm{FeCrAl}$, Zircaloy) in high-temperature steam conditions. Investigate the possibility eutectic formation and detrimental interaction among the various constituents of the fuel rod.

Output:

Produce report detailing oxidation kinetics for the separate effects tests.

Milestone 6.2.2.1: Summarize all findings into a written report.

Performance Period: October 2016 - December 2017

\subsection{THERMAL SHOCK}

In case of conventional urania pellets, cracking is expected early in fuel life as large temperature gradients develop across the fuel pellet. However, the FCM fuel pellets are designed in such a way to avoid any cracking during the fuel lifetime. Essentially, the temperature gradient across the fuel pellet is reduced, owing to improved thermal conductivity (even in the irradiated state) of SiC. On the other hand, the swelling gradient that develops across the pellet induces compressive stresses on the surface of the pellet. In this manner, cracking and exposure of TRISO particles to the rod plenum is not expected during normal operation of the pellet. However, situation could arise, for instance during a LB-LOCA sequence, where the swelling is annealed away and a sudden non-uniform quenching of the rod results in pellet cracking. The cracks are expected to be deflected by the OPyC layer as they arrive at the particle-matrix interface. However, if there is any failure in the TRISO particles, radionuclides could then be released to the outside of the pellet.

\subsubsection{Task I: High-Temperature Separate Effects Steam Oxidation of FCM Fuel Constituents}

\section{Objective:}

To assess the possibility and nature of cracking in FCM fuel pellets after quenching. Both individual pellet quench and rodlet quench cases need to be studied. While the former could be a result of a pellet discharge from the rod after burst, the latter is the expected case under design basis accidents.

Work Tasks:

Carry out quench testing of the FCM pellets and rodlets from $800^{\circ} \mathrm{C}$ or higher with room temperature (RT) water. The quench rate needs to be verified and proven to stay above the minimum limit expected during a rapid LB-LOCA transient. The pellets and the rodlet should then be examined for major cracking or micro-crack formation.

Output:

Produce report detailing oxidation kinetics for the separate effects tests.

Milestone 6.3.1.1: Summarize all findings into a written report.

Performance Period: April 2017 - June 2018 


\subsection{LOSS OF COOLANT ACCIDENT}

During a LOCA and certain BDBA the structural integrity of the FCM fuel and its ability to retain fission products are of central importance. For this reason the mechanical integrity and fission product release are to be determined as a function of off-normal LOCA conditions for fresh and as-irradiated fuels. This experimental campaign will be coordinated with the Fuel Qualification for Normal Operating Conditions campaign of Section 5.2.

Work Tasks:

Fuel materials for this irradiation will be prototypical FCM materials produced according to the Fuel Fabrication Plan (FFP-FCM-LTR-1) and Quality Assurance Plan (QAP-FCT-01) discussed in Section 4.3. Zircaloy cladding is to be chosen and qualified, replicating that of the eventual lead test rod application. Irradiation will be carried out utilizing the IFA at the HBWR and possibly the thermosyphon facility at ORNL or the ATR at the INL. Once desired burnup is reached seperate FCM fuel/clad pins will be transferred either into the HBWR LOCA testing rig and into the DOE-ORNL Severe Accident Test Facility for LOCA and beyon-design-basis accident testing. Table 6.4.1 provides a summary of the preinsertion burnup for each capsule and the desination test for the FCM-OffN qualification series.

Milestone 6.4.1: Experimental Matrix and QA Package for FCM-OffN series irradiation.

Performance Period: August 2015 - July 2016

Milestone 6.4.2: Interim Fuel Performance Report for FCM-OffN series irradiation: In-Core LOCA performance of FCM SiC-based fuel to $70 \mathrm{MWd} /$ tonne.

Performance Period: September 2016 - October 2019

Milestone 6.4.3: Interim Fuel Performance Report for FCM-OffN series irradiation: Steam-LOCA performance of FCM SiC-based matrix fuel to $70 \mathrm{MWd}$ /tonne.

Performance Period: September 2016 - October 2020

Milestone 6.4.4: Final Fuel Performance Report for FCM-OffN series irradiation: In-Core LOCA performance of FCM SiC-based matrix fuel to $160 \mathrm{MWd}$ /tonne.

Performance Period: September 2016 - December 2023

Milestone 6.4.5: Final Fuel Performance Report for FCM-OffN series irradiation: Steam-LOCA performance of FCM SiC-based matrix fuel to $160 \mathrm{MWd}$ /tonne.

Performance Period: September 2016 - December 2024 
Table 6.4.1: Summary of the FCM NO Fuel Qualification irradiation series to be carried out

in the HBWR and Severe Accident Test Facility.

\begin{tabular}{|c|c|c|c|c|}
\hline Facility & Capsule & I.D. & $\begin{array}{l}\text { Pre-Insertion } \\
\text { Burnup } \\
\text { MWd/tonne } \\
\text { And } \\
\text { Operation }\end{array}$ & Accident Test \\
\hline \multirow{13}{*}{ 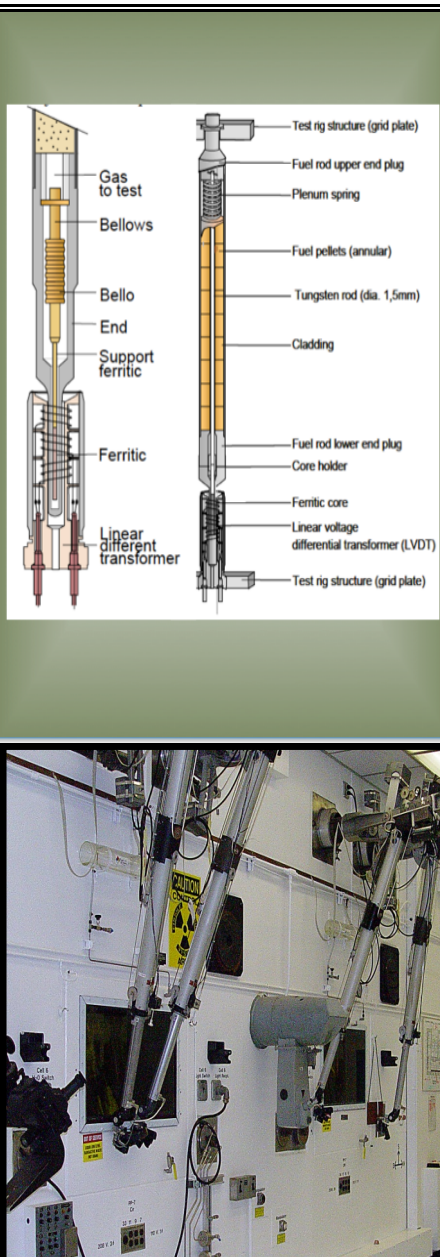 } & \multirow{13}{*}{$\begin{array}{l}\text { FCM- } \\
\text { OffN }\end{array}$} & Pin U-1 & $\begin{array}{c}160 \\
\text { steady state }\end{array}$ & LOCA-HBWR \\
\hline & & Pin U-2 & $\begin{array}{c}160 \\
\text { load follow }\end{array}$ & LOCA-HBWR \\
\hline & & Pin U-3 & $\begin{array}{c}125 \\
\text { steady state }\end{array}$ & LOCA-HBWR \\
\hline & & Pin U-4 & $\begin{array}{c}70 \\
\text { steady state }\end{array}$ & SATS-ORNL \\
\hline & & Pin U-5 & $\begin{array}{c}130 \\
\text { steady state }\end{array}$ & LOCA-HBWR \\
\hline & & Pin U-6 & $\begin{array}{c}160 \\
\text { steady state }\end{array}$ & LOCA-HBWR \\
\hline & & Pin L-1 & $\begin{array}{c}70 \\
\text { steady state }\end{array}$ & SATS-ORNL \\
\hline & & Pin L-2 & $\begin{array}{c}130 \\
\text { steady state }\end{array}$ & SATS-ORNL \\
\hline & & Pin L-3 & $\begin{array}{c}160 \\
\text { steady state }\end{array}$ & - \\
\hline & & Pin L-4 & $\begin{array}{c}70 \\
\text { load follow }\end{array}$ & - \\
\hline & & Pin L-5 & $\begin{array}{c}160 \\
\text { load follow }\end{array}$ & SATS-ORNL \\
\hline & & Pin L-6 & $\begin{array}{c}160 \\
\text { steady state }\end{array}$ & - \\
\hline & & & & \\
\hline
\end{tabular}

\subsection{REACTIVITY INSERTION}

Both reactivity insertion and reactor power ramp events are potential vectors that may lead to loss of fission product retention of the FCM fuel. Moreover, the allowed ramp rate during normal start-up and shut down and the potential for stress-induced rupture of the FCM matrix are parameters which need to be addressed. This is especially important as a function of burnup as matrix stress is directly linked to thermal conductivity which degrades substantially as a function of burnup (fast neutron irradiation.)

Work Tasks:

Fuel materials for this irradiation will be prototypical FCM materials produced according to the Fuel Fabrication Plan (FFP-FCM-LTR-1) and Quality Assurance Plan (QAP-FCT-01) discussed in Section 4.3. Zircaloy cladding is to be chosen and qualified, replicating that of the eventual lead test rod 
application. An irradiation campaign utilizing drop-in ATR capsules to achieve desired burnup followed by transient testing in the TREAT facility will be carried out. Table 6.5 .1 provides a summary of the preinsertion burnup for each capsule and the desination test for the FCM-T qualification series. Two general types of irradiation experiments are to be carried out: FCM-T-RI series, which consists of ATR accumulated burnup on LWR candidate FCM fuel followed by TREAT reactivity insertion at 50, 100, and $200 \mathrm{~ms}$. Second, the FCM-T-PR series, which consists of ATR accumulated burnup on LWR candidate FCM fuel followed by TREAT power ramp testing from 10 seconds down to 2 seconds.

Milestone 6.5.1: Experimental Matrix and ATR Irradiation QA Package for FCM-TR and FCM-RI series irradiation.

Performance Period: August 2016 - July 2017

Milestone 6.5.2: Final Fuel Performance Report for FCM-RI series irradiation.

Performance Period: August 2019 - October 2020

Milestone 6.5.3: Final Fuel Performance Report for FCM-RI series irradiation.

Performance Period: August 2020 - October 2021

Table 6.5.1: Summary of the FCM Reactivity Insertion (RI) experiment.

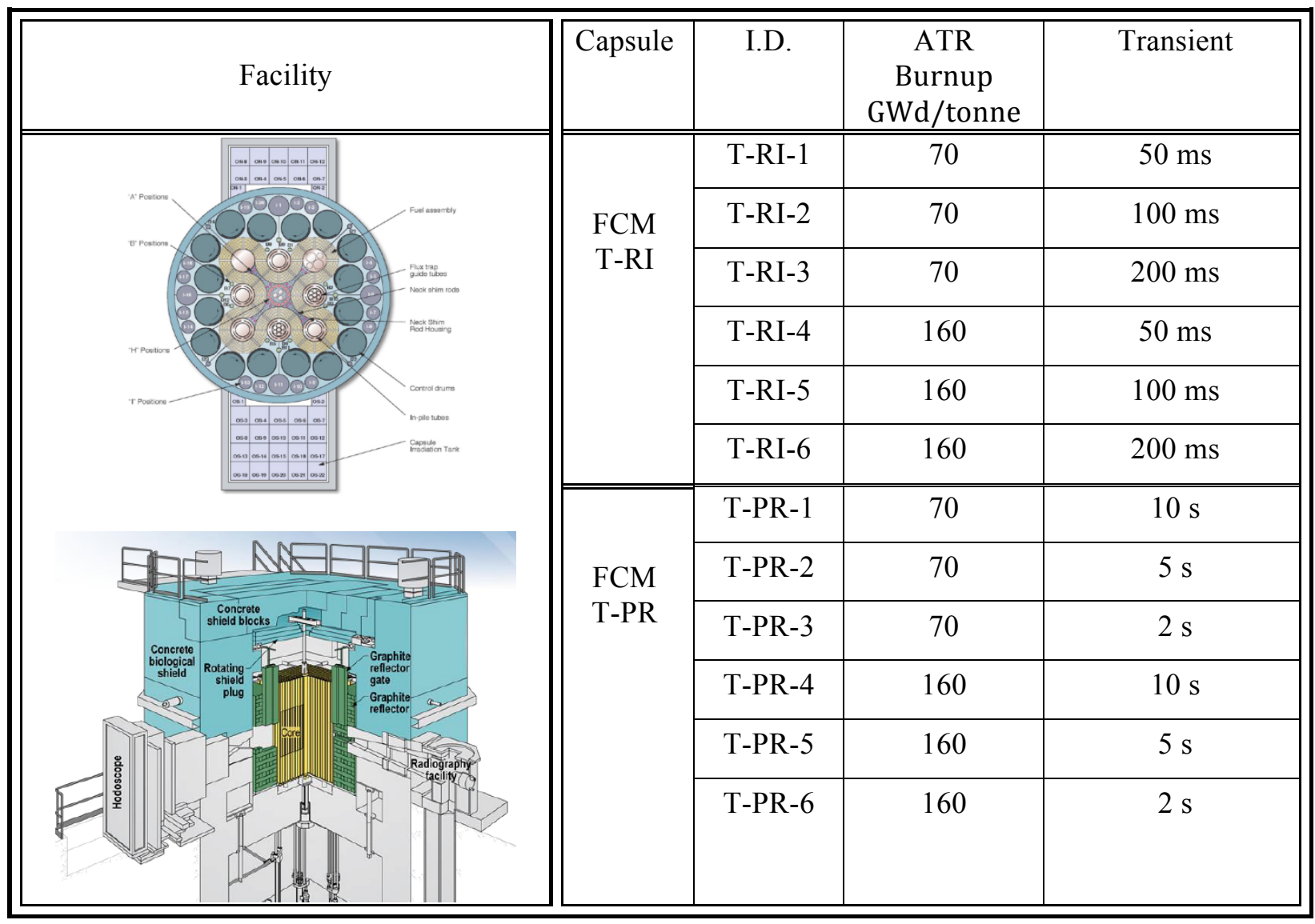




\section{REFERENCES}

[1] L. L. Snead; K. A. Terrani; F. Venneri; Y. Kim; J. E. Tulenko; C. W. Forsberg, et al., Transactions of the American Nuclear Society 2011, 104.

[2] K. A. Terrani; L. L. Snead; J. C. Gehin, Journal of Nuclear Materials 2012, 427 (1-3), 209-224.

[3] D. Petti; J. Maki; J. Hunn; P. Pappano; C. Barnes; J. Saurwein, et al., JOM Journal of the Minerals, Metals and Materials Society 2010, 62 (9), 62-66.

[4] J. McDuffee; J. Carbajo; D. Felde, Design, Fabrication, and Modeling of a Two-Phase Thermosyphon Experimental Facility for Fuels and Materials Irradiation. In Proceedings of WRFPM 2014, Sendai, Japan, 2014; p Paper No. 100082.

[5] J. Hales; R. Williamson; S. Novascone; D. Perez; B. Spencer; G. Pastore, Journal of Nuclear Materials 2013, 443 (1), 531-543.

[6] C. Gentry; I. Maldonado; A. Godfrey; K. Terrani; J. Gehin; J. Powers, Nuclear Technology 2014, 186 (1).

[7] N. M. George; I. Maldonado; K. A. Terrani; A. Godfrey; J. Gehin; J. Powers, Nuclear Technology 2014, $188(3)$.

[8] N. George; I. Maldonado; K. Terrani; A. Godfrey; J. Gehin Neutronics studies of uranium-based fully ceramic micro-encapsulated fuel for PWRs; American Nuclear Society, Inc., 555 N. Kensington Avenue, La Grange Park, Illinois 60526 (United States): 2012.

[9] N. R. Brown; H. Ludewig; A. Aronson; G. Raitses; M. Todosow, Annals of Nuclear Energy 2013, 62, 538-547.

[10] J. D. Hunn; R. A. Lowden Data compilation for AGR-1 baseline coated particle composite LEU0146T; Oak Ridge National Laboratory (ORNL); Shared Research Equipment Collaborative Research Center: 2006.

[11] T. B. Lindemer; S. L. Voit; C. M. Silva; T. M. Besmann; R. D. Hunt, Journal of Nuclear Materials 2014, 448, 404-411.

[12] Y. Katoh; A. Kohyama; T. Nozawa; M. Sato, Journal of Nuclear Materials 2004, 329-333, 587-591. [13] L. L. Snead; K. A. Terrani; Y. Katoh; C. Silva; K. J. Leonard; A. G. Perez-Bergquist, Journal of Nuclear Materials 2014, 448, 389-398.

[14] K. A. Terrani; J. O. Kiggans; Y. Katoh; K. Shimoda; F. C. Montgomery; B. L. Armstrong, et al., Journal of Nuclear Materials 2012, 426 (1-3), 268-276.

[15] K. A. Terrani; J. Kiggans; C. M. Silva; C. Shih; Y. Katoh; L. L. Snead, Journal of Nuclear Materials 2015, 457, 9-17.

[16] D. Olander; Y. S. Kim; W.-E. Wang; S. K. Yagnik, Journal of nuclear materials 1999, 270 (1), 11 20.

[17] T. Cheng; J. R. Keiser; M. P. Brady; K. A. Terrani; B. A. Pint, Journal of Nuclear Materials 2012, 427, 396-400.

[18] M. Steinbrück; M. Große; L. Sepold; J. Stuckert, Nuclear Engineering and Design 2010, 240 (7), 1714-1727.

[19] K. A. Terrani; B. A. Pint; C. M. Parish; C. M. Silva; L. L. Snead; Y. katoh, Journal of American Ceramic Society 2014, 97 (8), 2331-2352.

[20] K. A. Terrani; C. M. Silva, Journal of Nuclear Materials 2015, 460, 160-165. 